\title{
عناصر نطاق الملكية العقارية الخاصة في التشريع الجزائري
}

$$
\begin{aligned}
& \text { د.عمّار نكاع } \\
& \text { كلية الحقوق } \\
& \text { جامعة الإخوة منتوري } \\
& \text { الجز ائر }
\end{aligned}
$$

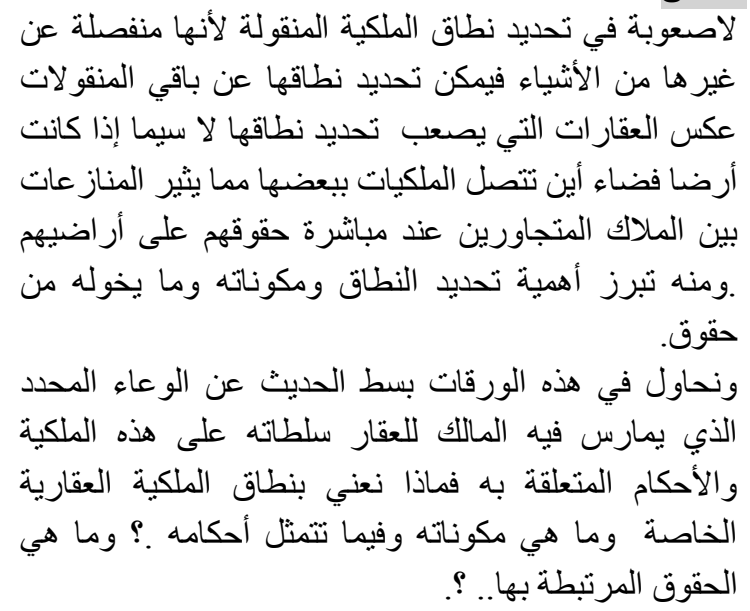

\section{مقدّمة:}

أن حق الملكية عموما وحق الملكية العقارية

\section{Abstract:}

No difficulty in identifying movable domain because it is separate from other things can determine the scope of the rest of movables unlike real estate, which is difficult to determine its scope, especially if the ground space where related properties to each other, raising disputes between landlords neighbors when exercising their rights on their land. And this is what It highlights the importance of defining the scope and its components and authorized rights. We try in these papers talk about the extension of the specified container in which the owner of the property shall exercise its powers on this property and provisions related to the scope of what we mean private property ownership and what are its components and is in its provisions.? What are the rights associated with it ..?. 
جاره على وضع حدود لأملاكهما المتلاصقة .فماذا نعني بالنطاق وما هي مشمو لاته وفيما تتمثل أحكامها. ؟ وما هي الحقوق المنوطة بنطاق الملكية العقارية.. ؟

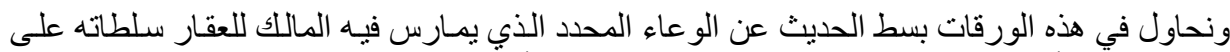

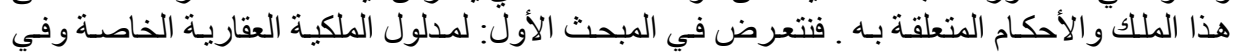
المبحث الثاني: نتطرق لعناصر نطاق هذه الملكية .

\section{المبحث الأول: مدلول الملكية العقارية الخاصة:}

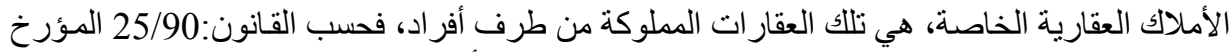

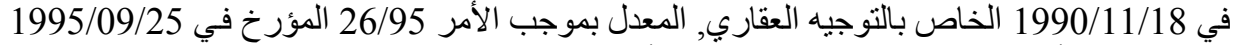
الذي صنف الأملاك العقارية في مادته 23 إلى الأصناف الكانية القانونية التالية:

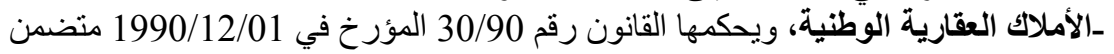

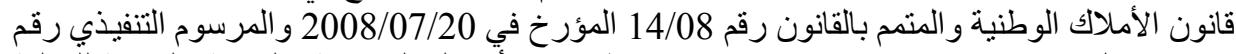

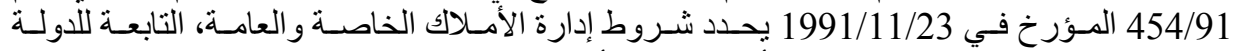

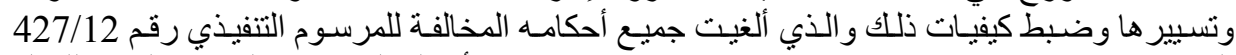

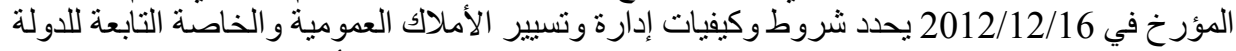

و المرسوم التنفيذي رقم 455/91 المؤرخ في 1991/11/23 متعلق بجرد المارد الأملاك الوطنية.

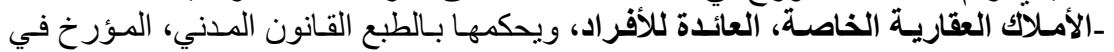

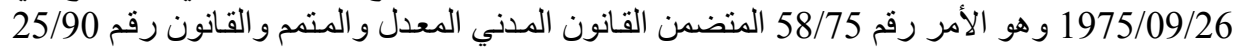
السالف الذكر و الفانون رقم 04/11 المؤرخ في 2011/02/17 يحدد القو اعد التي تنظم نشـاط الترقيـة

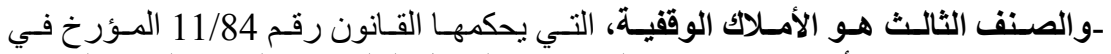

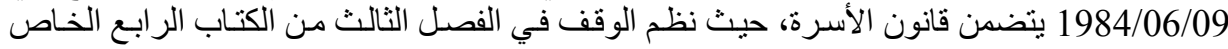

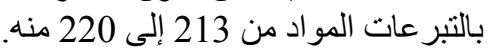

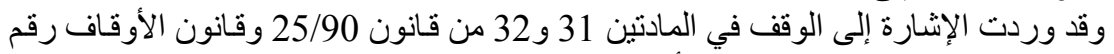

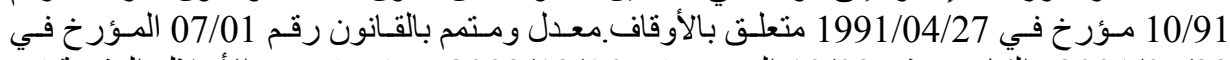

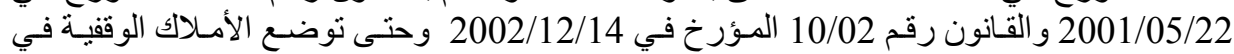

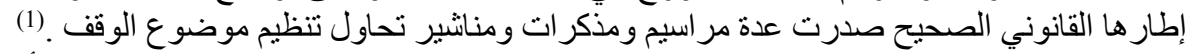

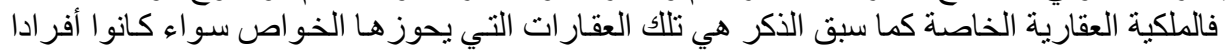
طبيعيين، أو كانو ا أشخاص معنوية خاصة، مثل الجمعيات و الثركات.

\section{المطلب الأول :تعريف الملكية العقارية الخاصة :}

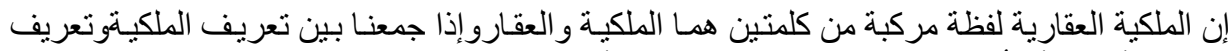

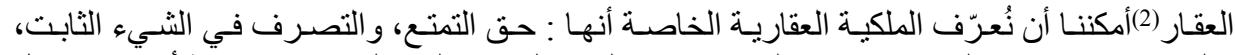

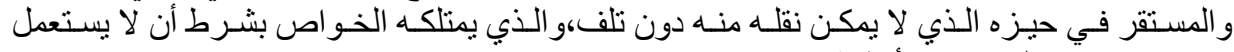
استعمالا تحرمة القو انين والأنظمة. الأبكن.

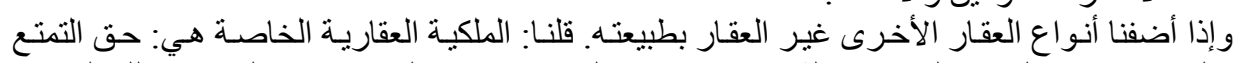

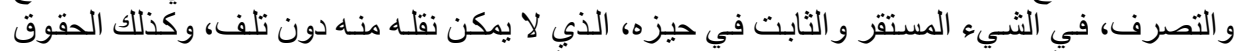
العينية، بشرط أن لا يستعمل استعمالا تحرمة القو انين و الأنظمة. 


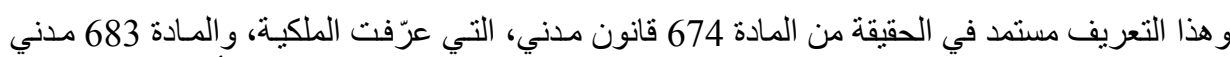

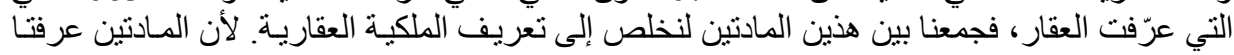

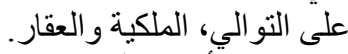

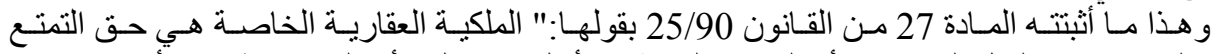

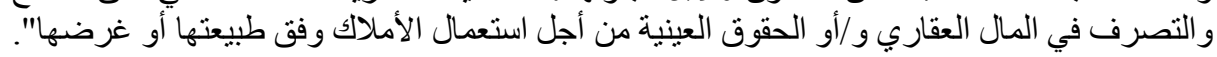

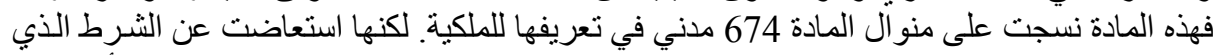

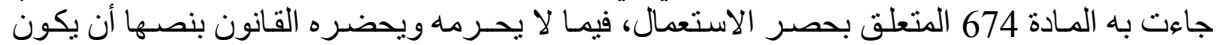
الاستعمال وفق طبيعة الأملاك أو غرضنها.

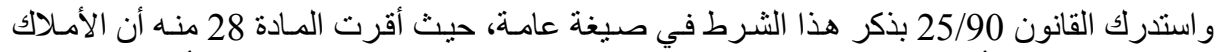

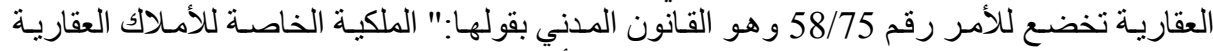
والحقوق العينية العقارية يضمنها الدستور وتخضيع للأكر رقم

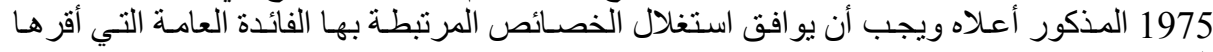

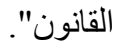

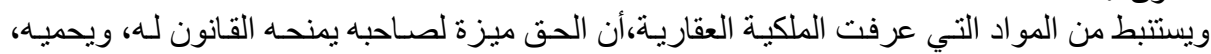

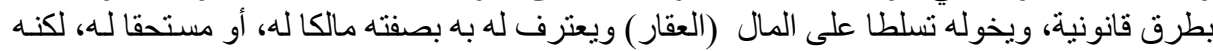

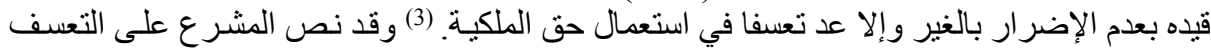

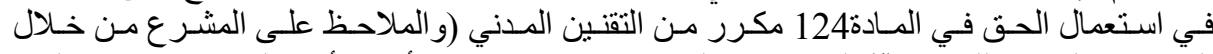

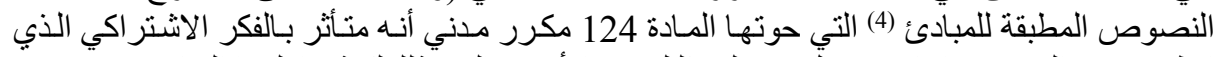

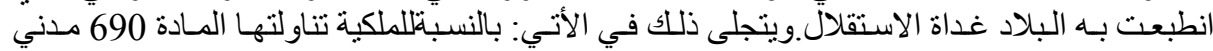

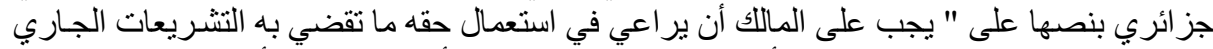

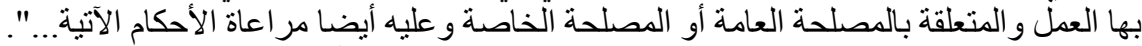

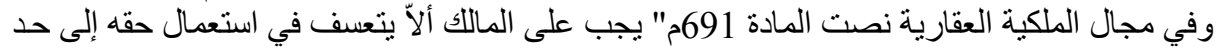

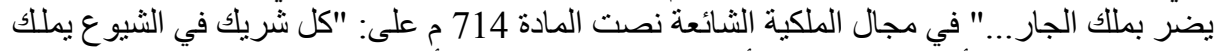

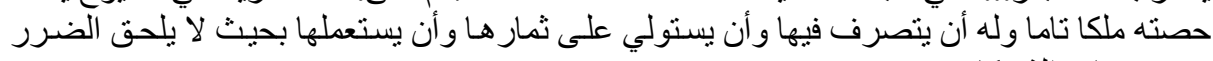

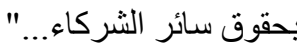
أما في مجال الحقوق التابعة لحق الملكية العقاريـة فقد جاءت تطبيقات مبادئ المسادة 124 مكرر في

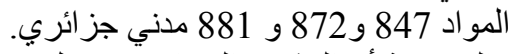

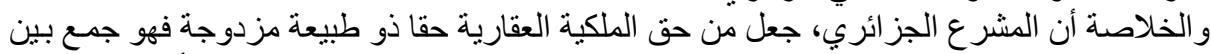

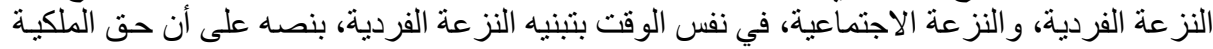

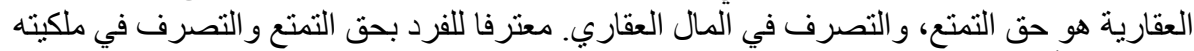

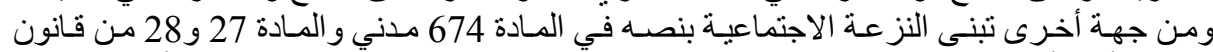

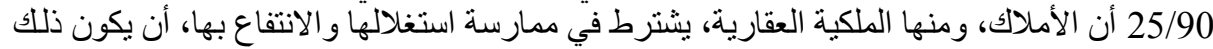

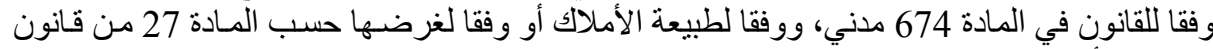

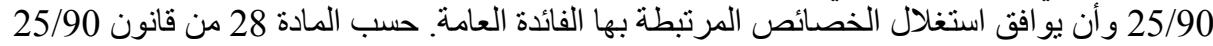

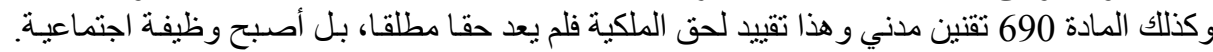

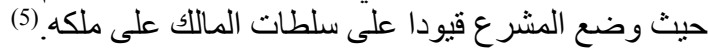

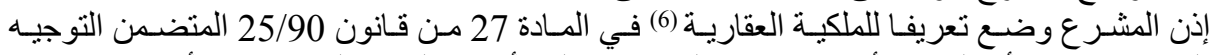

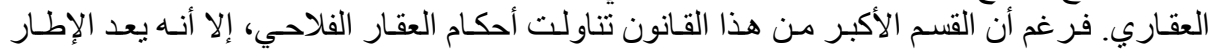

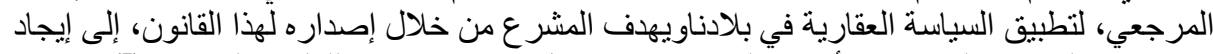

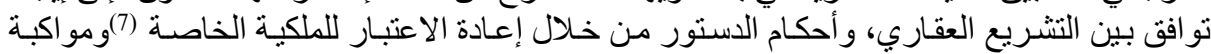

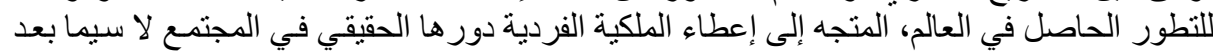


سقوط المعسكر الشرقي لكن هذا التطور للملكية الفردية ذو بعد اجتماعي كما أسلفنا، فالملكية أضحت

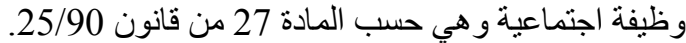

"الملكية العقارية الخاصية هي حق التمتع و التصرف في في المال العقاري و / أو الحقوق العينية من أجل

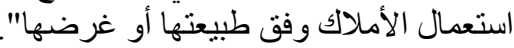

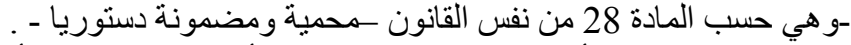

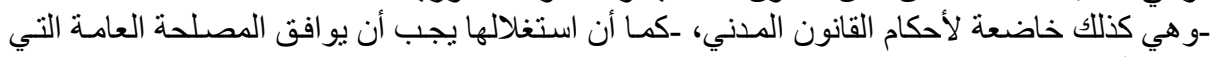

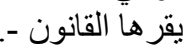

المطلب الثاني: أنواع الملكية العقارية الخاصة:

تختلف الملكية باختلاف وجهة النظر إليها، فإذا نظرنا إلى إليها باعتبار محلها وجدنا أنها ملكية واردة على

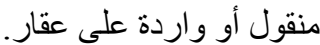

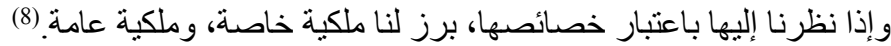

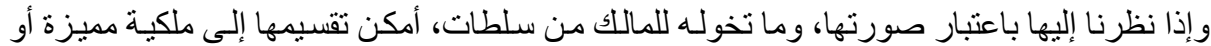
تامة وملكية شائعة.

وباستقر اء القانون المدني نجده قد نظم أحكام الملكية، وبين أنو اعها ابتداء من المـادة 674 و ومـا بعدها.

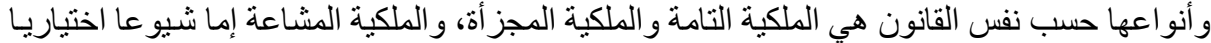

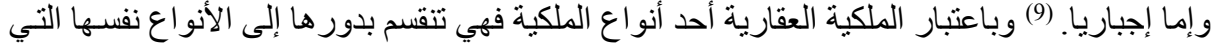

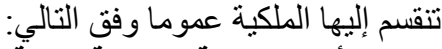
الفرع الأول: الملكية العقارية التامة: التئية

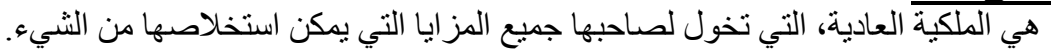

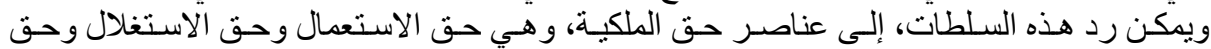

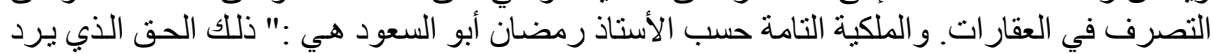

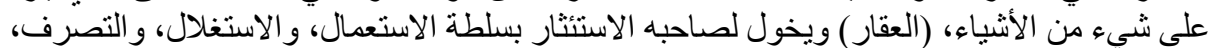

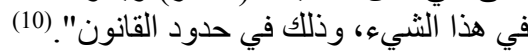

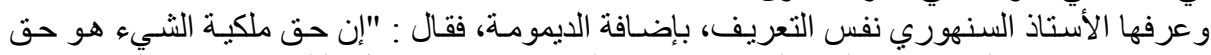

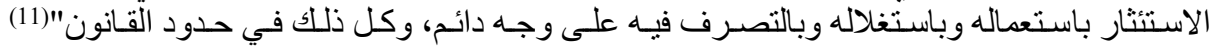

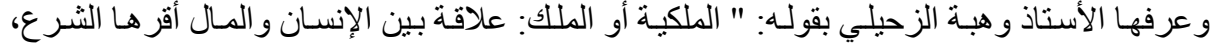

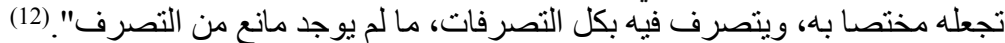

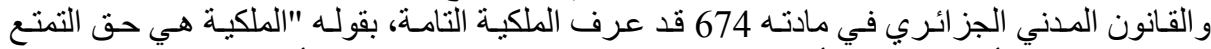

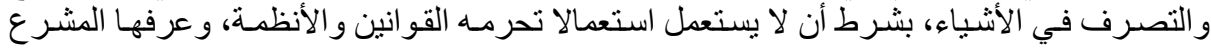

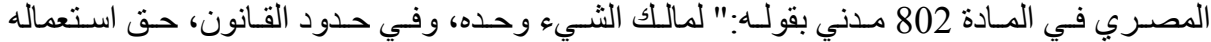

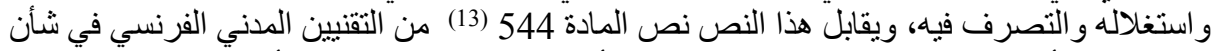
حق الملكية بأنها :"هي حق التمتع و التصرف في الأشياء بطريقة مطلقة بشرط أن لآ تستعمل استعمالا

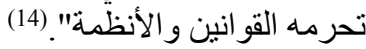

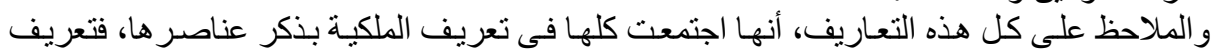

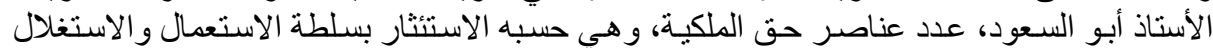

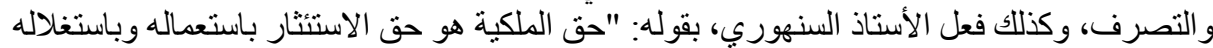

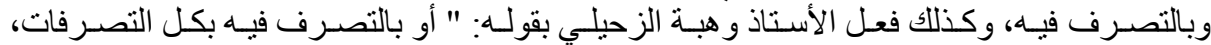

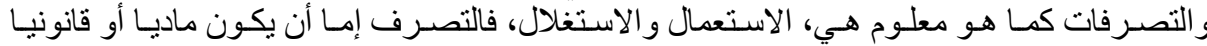
والتصرف المادي يشمل الاستغلال و الاستعمال.

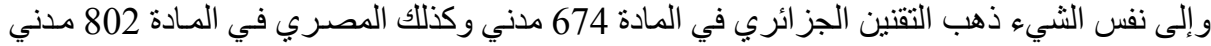
مصري، ونفس الثيء فعله المشرع الفرنسي في المادة 544 مدني فرنسي. 


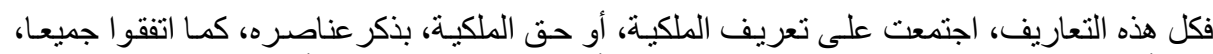

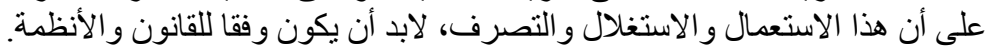

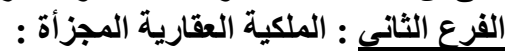



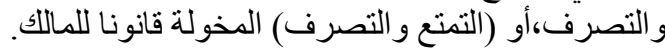

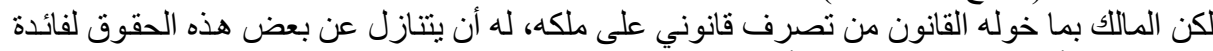

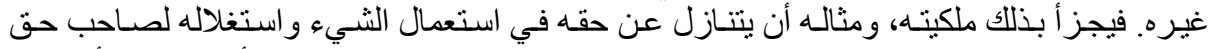

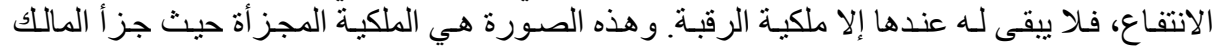

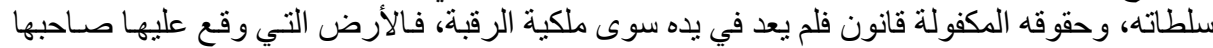

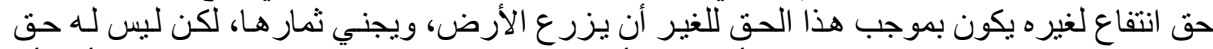

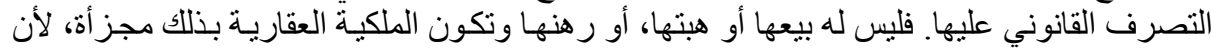

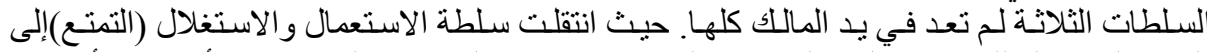

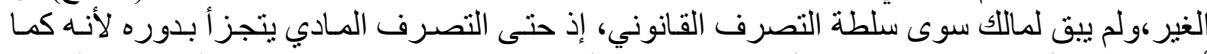

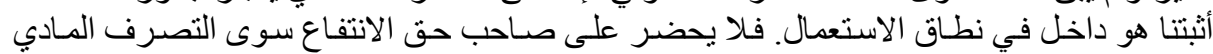

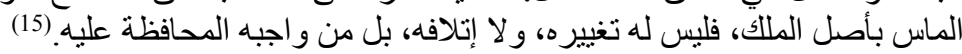

الفرع الثالث : الملكية العقارية المشاعة :

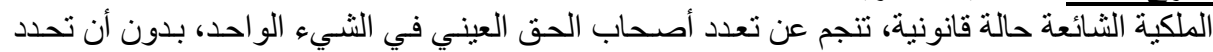

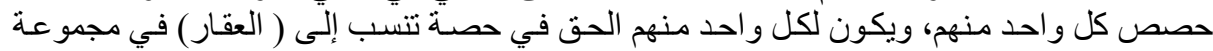
كالنصف أو الربع أو الثلث. (16) عرفها المشر ع الجز ائري في المادة 713 من القانون المدني بقوله : "إذا ملك الثنان أو أكثر شيئا وكانت حصة كل منهم فيه غير مقررة فهم شركاء على الثيو ع وتعتبر الحصص منساوية إذا لم يقم دليل على الى الئل

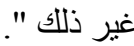
الملاحظ على هذا النص ، أن المشر ع استخدم لفظة ( الثيء) و هذا معنـاه دخول العقار و المنقول،

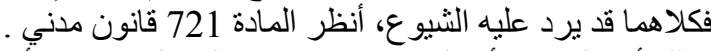

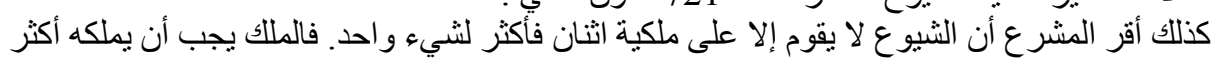
من شخص و احد،حتى تكون بصد المن ملكية شائعة.

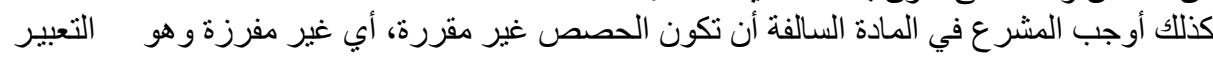

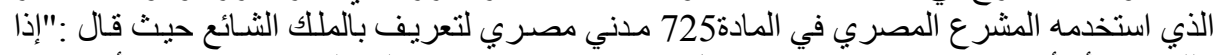

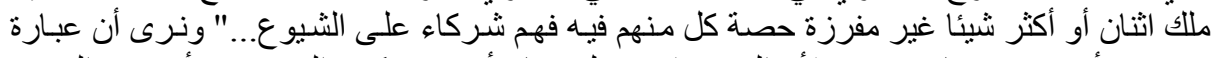
(مفرزة) أنسب من عبارة مقررة لأن التقرير قد يحمل معان أخرى عكس الفرز فهي فهو أدق في التعبير

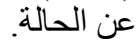

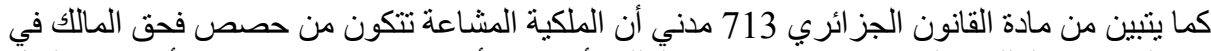

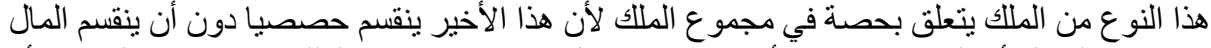

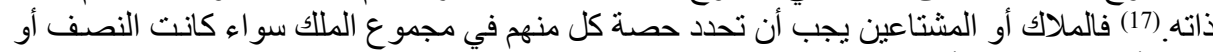

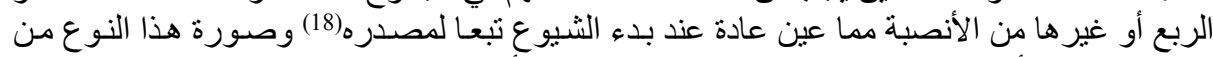

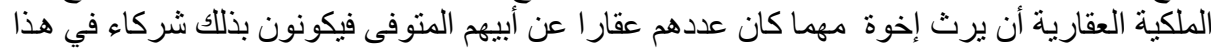

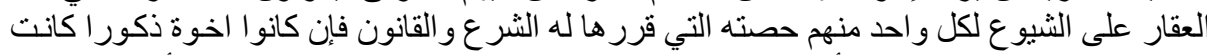

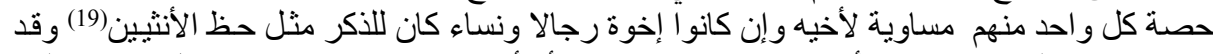

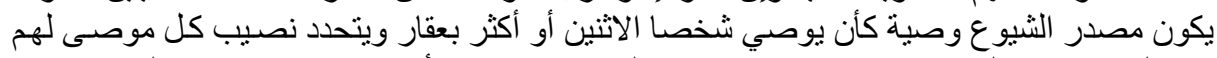

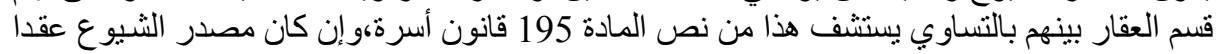




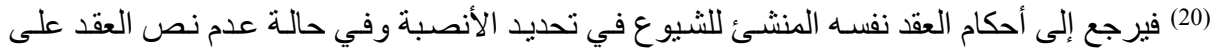

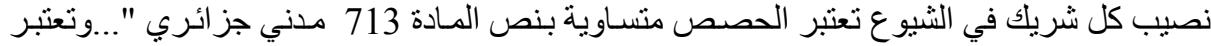

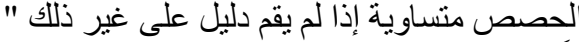

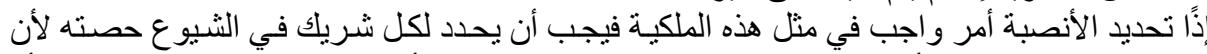

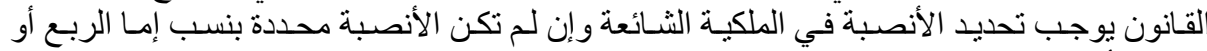

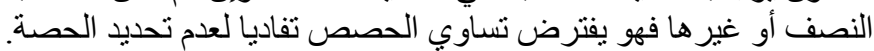

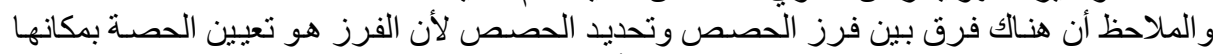

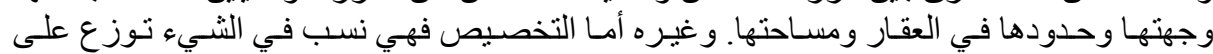

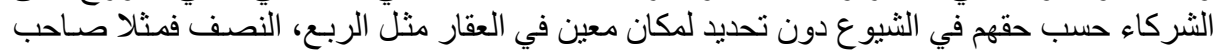

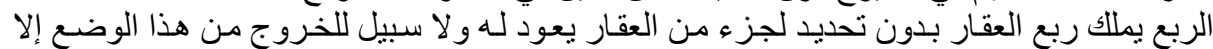

بالقسمة الودية أو القسمة القضائية.

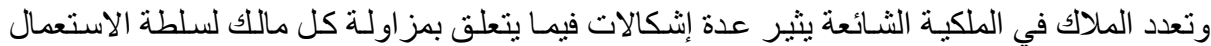

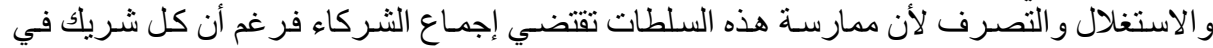

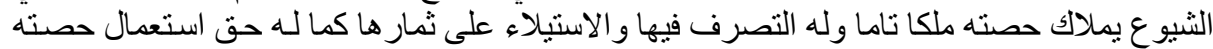

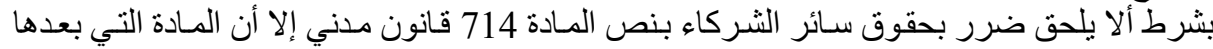

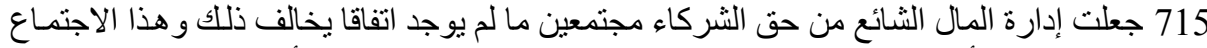

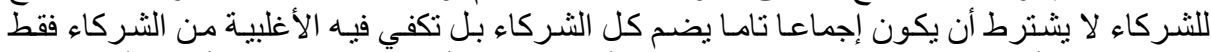

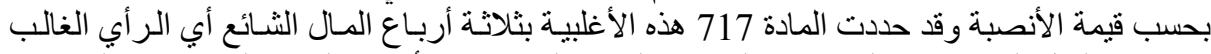

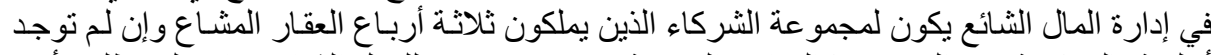

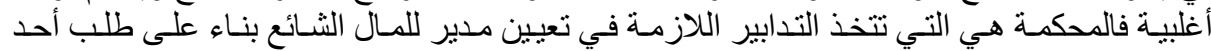

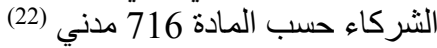

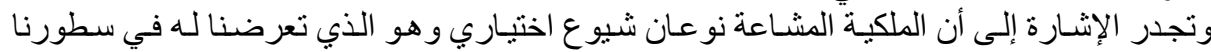

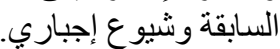

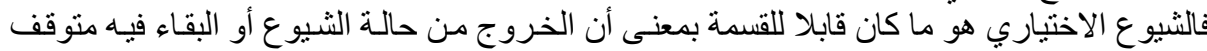

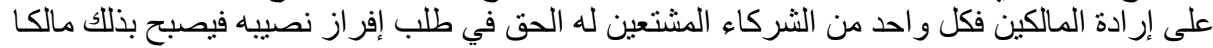

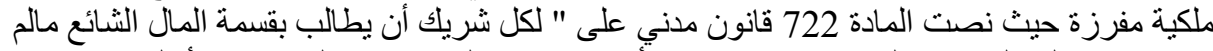

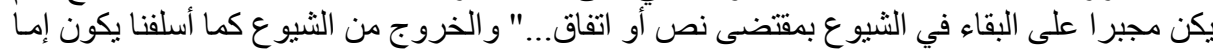

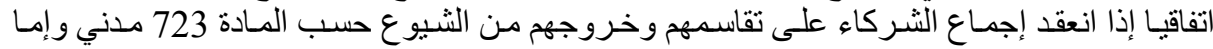

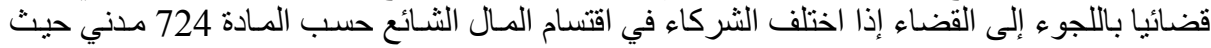

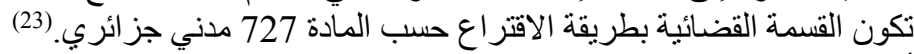

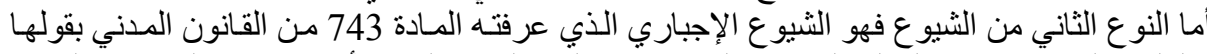

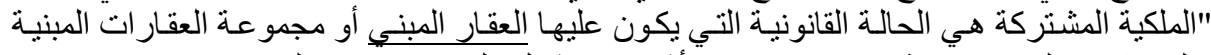

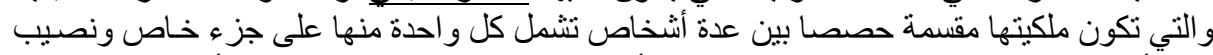

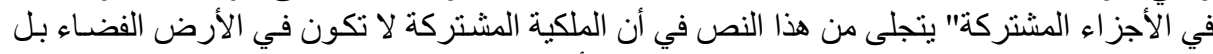

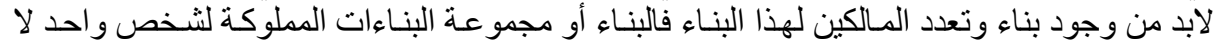

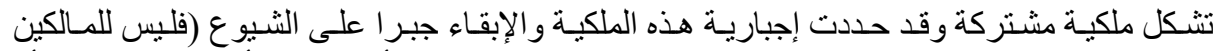

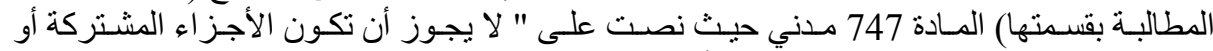

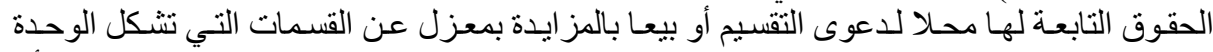

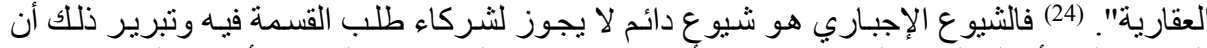

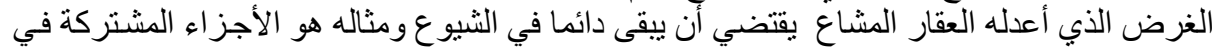

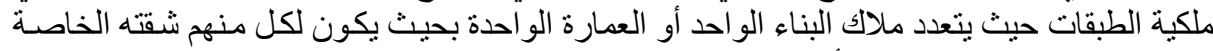

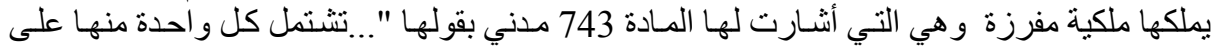




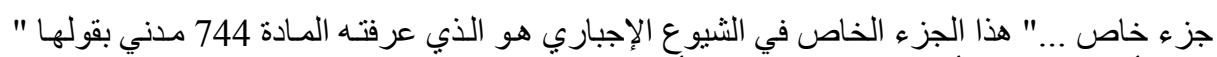

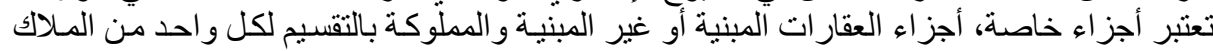

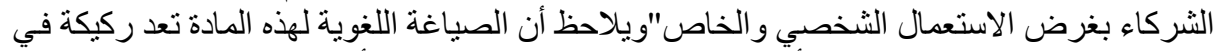

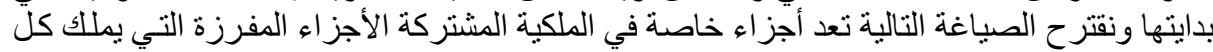

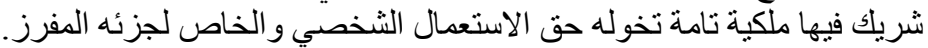

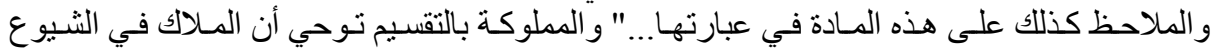

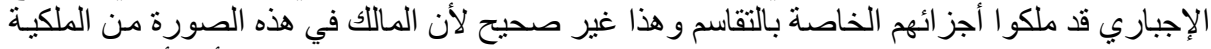

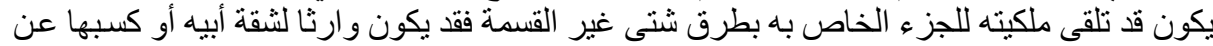

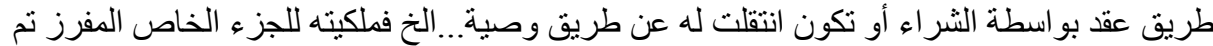

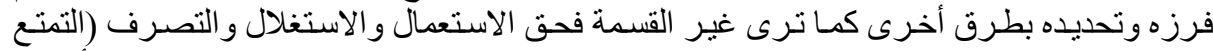

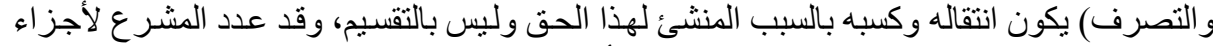

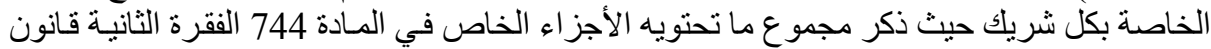

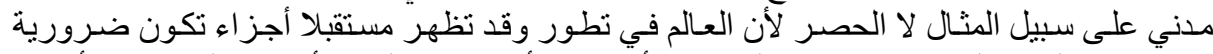

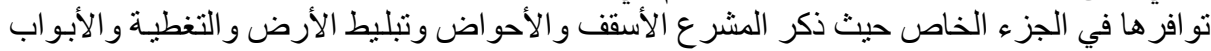

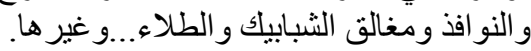

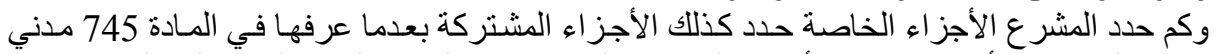

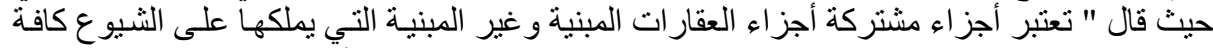

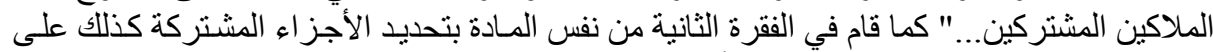

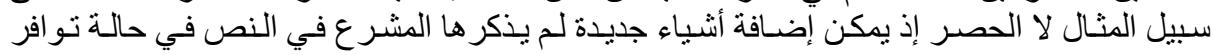

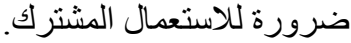

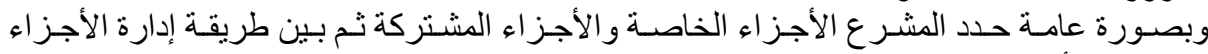

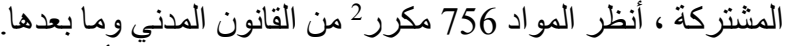

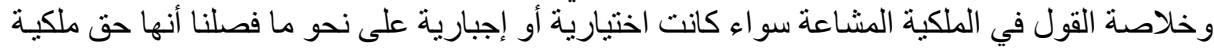

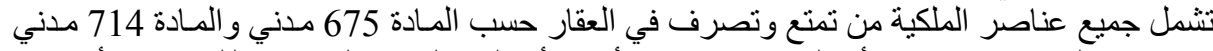

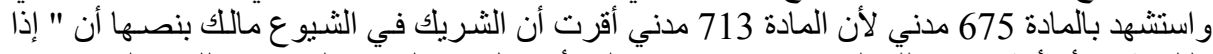

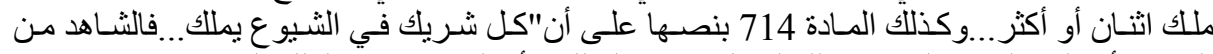

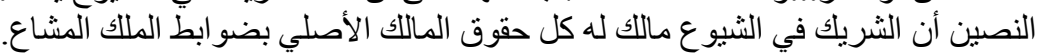

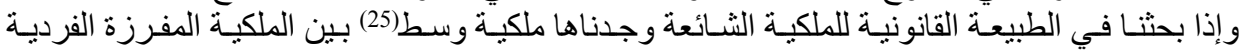

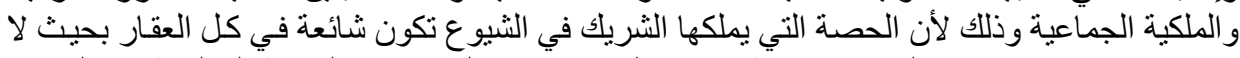

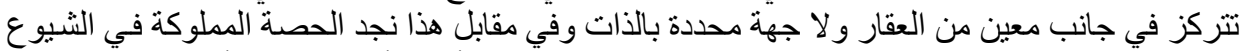

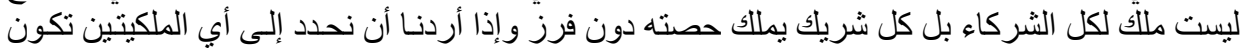

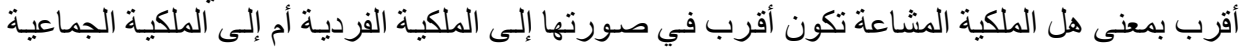

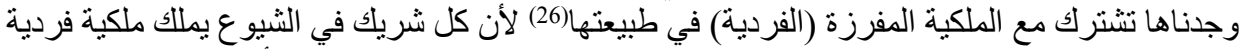

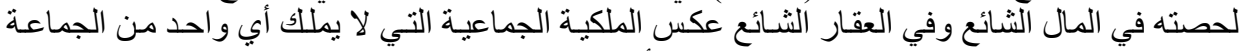

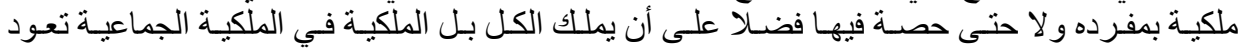

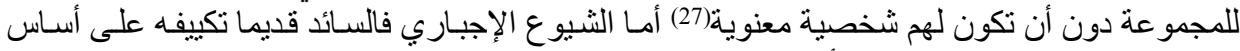

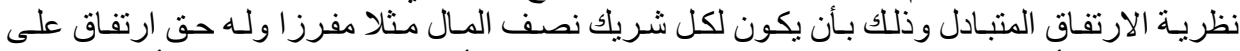

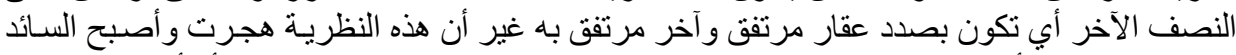

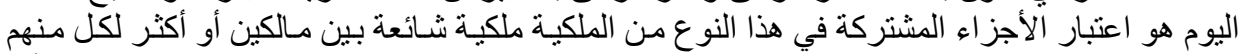

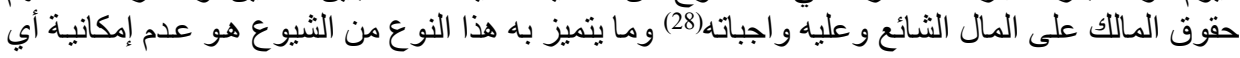


شريك المطالبة بقسمته لأن حالة الضرورة التي أملت هذه الحالة من الثشيوع الإجباري تقتضى بقاؤه كذلك

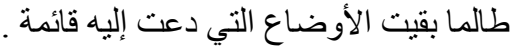

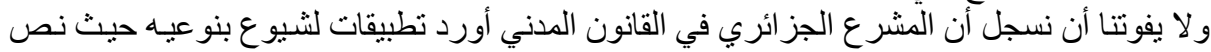

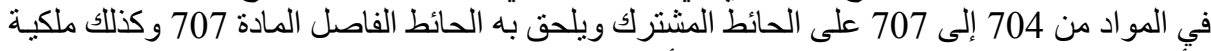

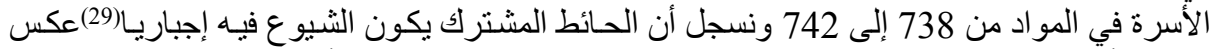

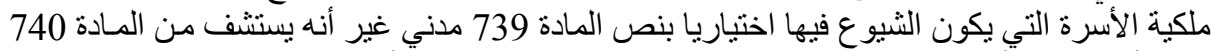

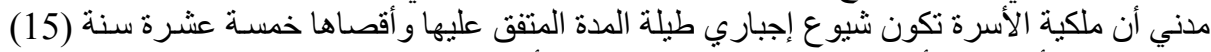

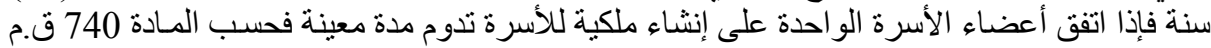

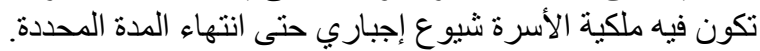

المطلب الثالث :عناصر الملكية العقارية الخاصة:

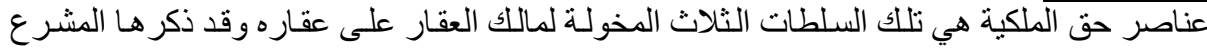

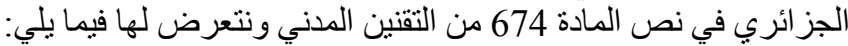

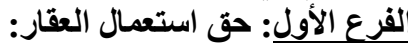

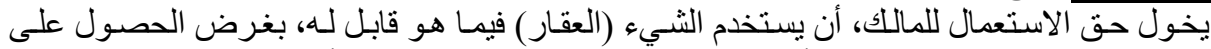

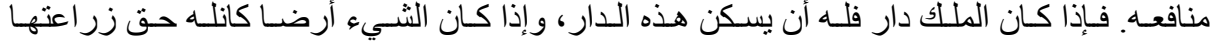

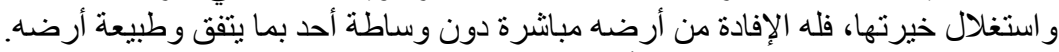

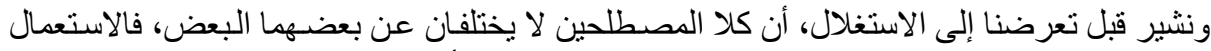

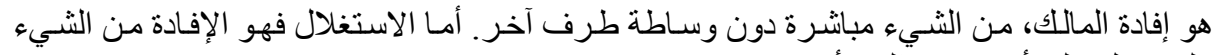
بالحصول على أجرته من المستأجر.

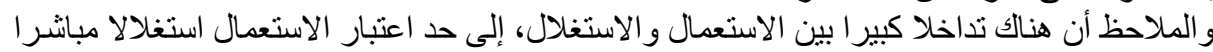

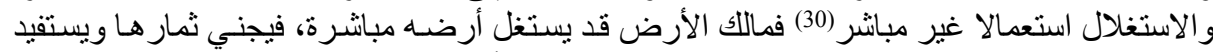

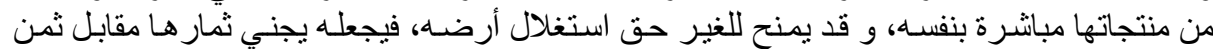

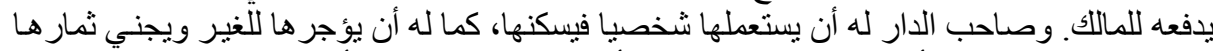

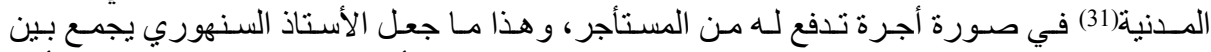

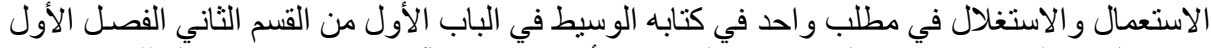

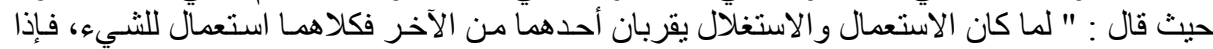

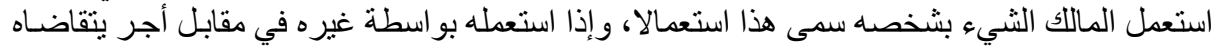

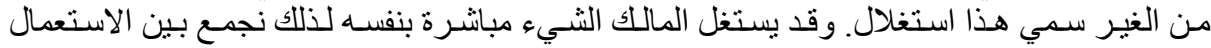

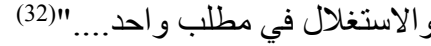

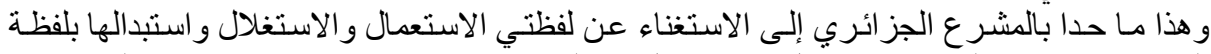

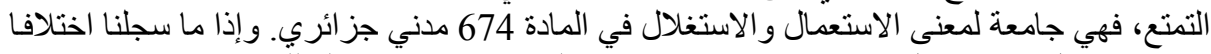

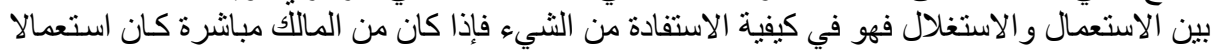

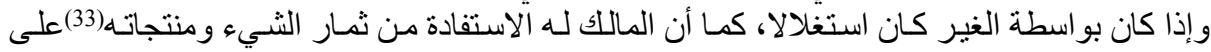

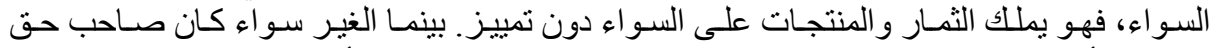
الانتفاع، أو حسائز فليس لـه الحق إلا في الثمـار بشروط حددهاء القانون أنظر المواد 837 مدني ومـا

لكن قد تتحول المنتجات إلى ثمـار وبالتـالي يستطيع غير الماللك الإفـادة منها إذا أعد الثـيء إعداداد

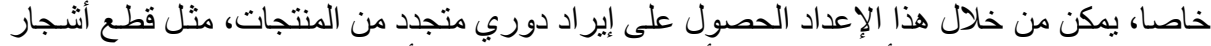

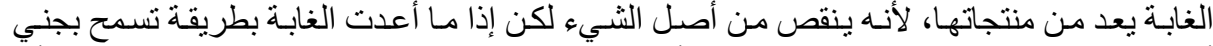

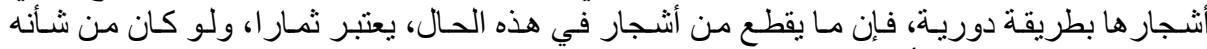
المساس بجو هر الثيء وأصله. 
فإذا مـا تقرر لثخص حق انتفاع على هذه الغابـة ، بعد أن أعدت هذا الإعداد كان للمنتفع أن يقطع

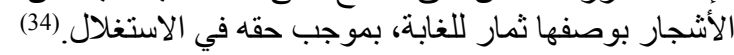

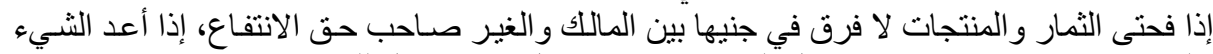

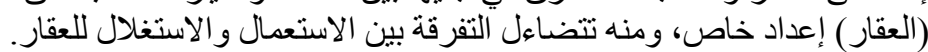

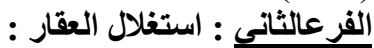

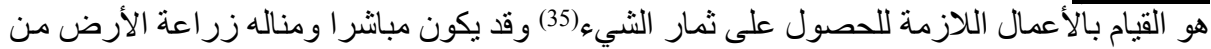

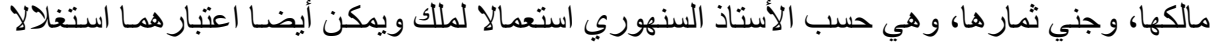

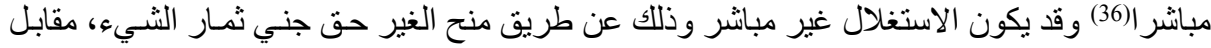

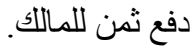

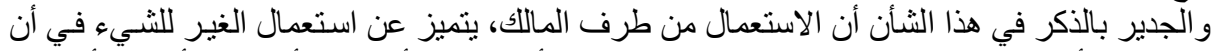

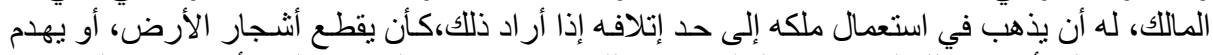

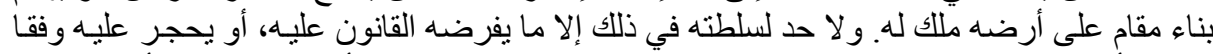

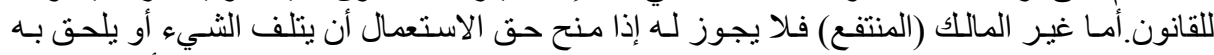

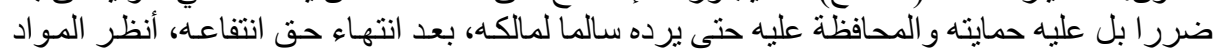

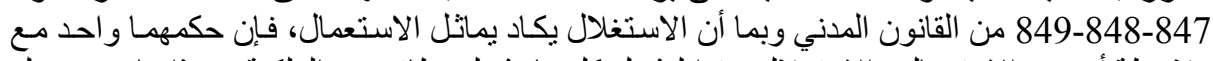

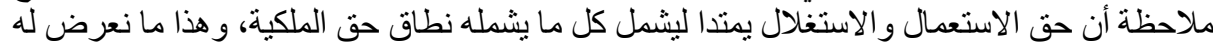

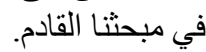

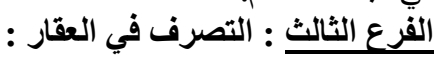

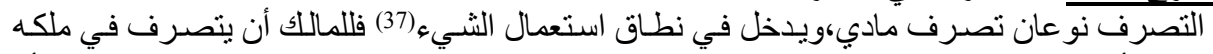

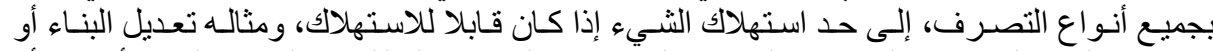

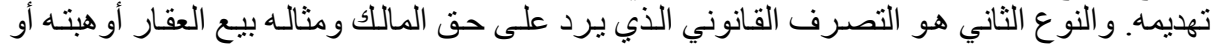

فالأول هو العمل المادي الذي ينال من ( العقار )، و هو كما أسلفنا يختلط بالاستعمال.

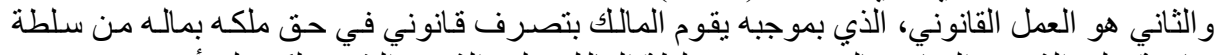

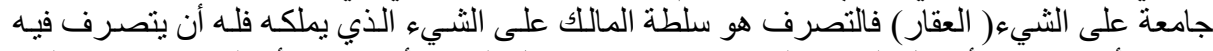

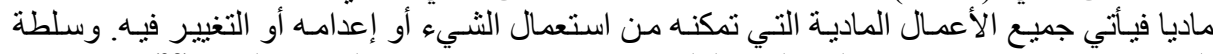

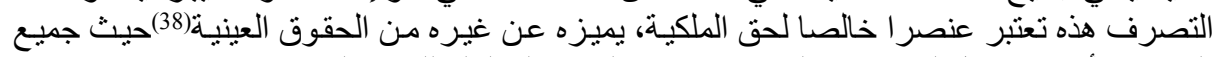

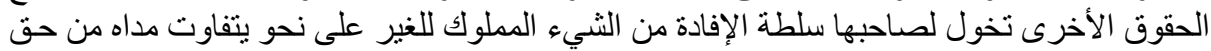

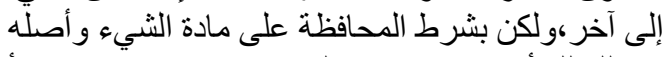

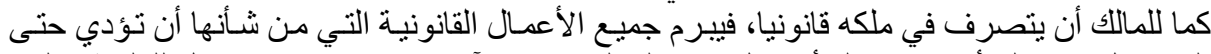

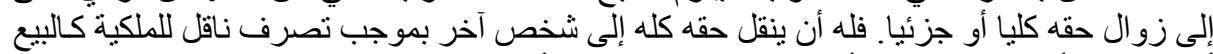

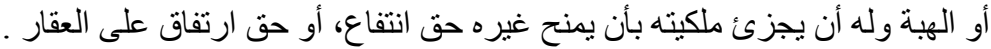

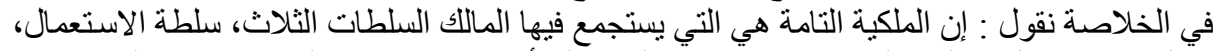

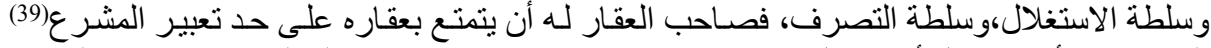

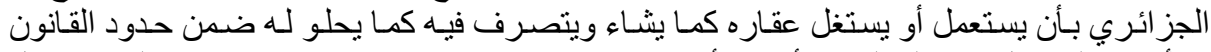

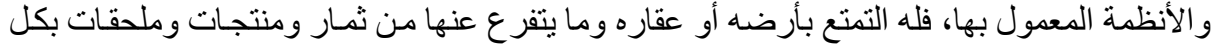

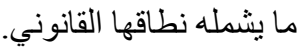

المبحث الثاني:عناصر نطاق الملكية العقارية الخاصة : 


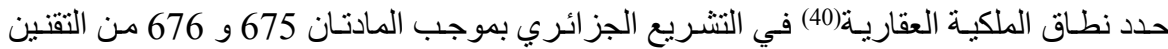

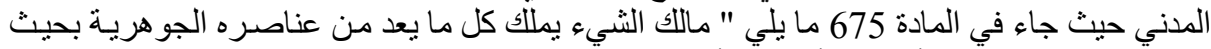
لا يمكن فصله عنه دون أن يفسد أو يتلف أو يتغير.

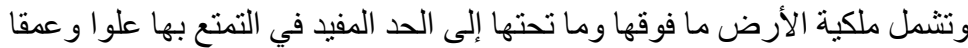
ويجوز بمقتضى القانون أو الاتفاق أن تكون ملكية سطح الأرض منفصلة عن ملكية ما فو قها أو تحتها" وجاء في المادة 676 ما يلي " لمالك الثيء الحق في كل ثماره ومنتجاته وملحقاته مالم بوجد نص أو

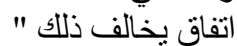
يتبين إذا من هذين النصين أن نطاق الملكية العقارية هو الو عاء المحدد الذي يمارس فيه المالك سلطاته

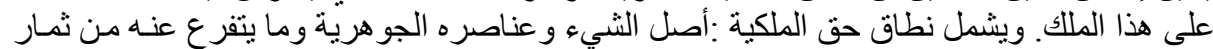

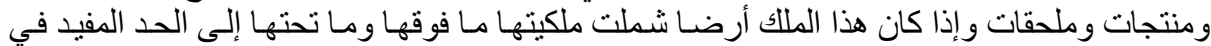

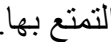

ومن خلال النصبن السالفين يمكن استخلاص المبادئ التالية إذ في مجال نطاق الملكية تدخل العناصر التالية :

1-شمولية نطاق الملكية أول ما تشمل الثيء نفسه (أصل الثنيء).

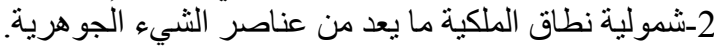

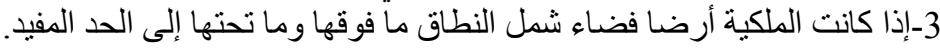
4-يشمل كذلك نطاق الملكية ثمار الثيء الثيك ومنتجاته وملحقاتها

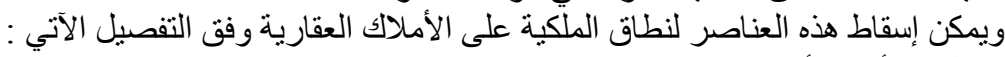

المطلب الأول : أصل الثيء الثئ(العقار)

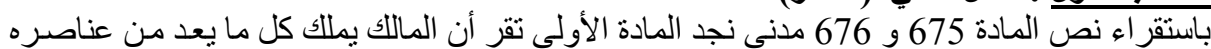

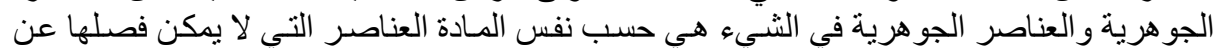

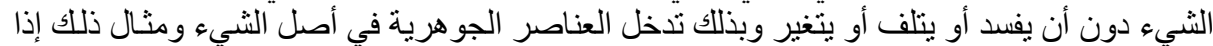

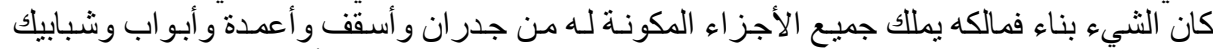

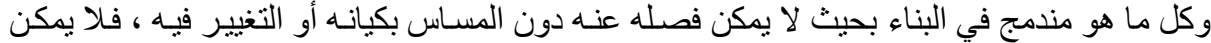

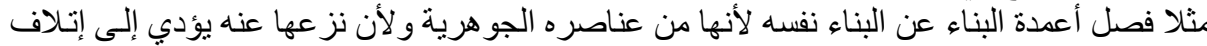

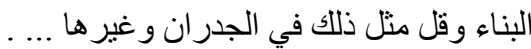

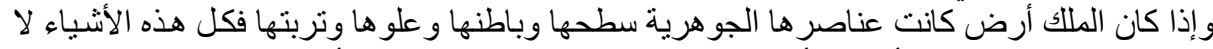

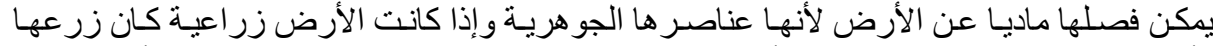

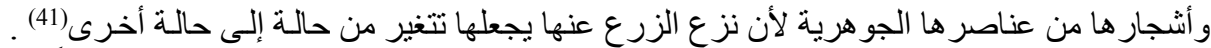

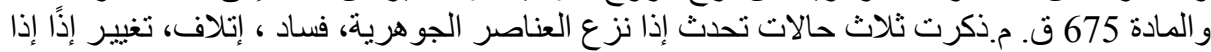

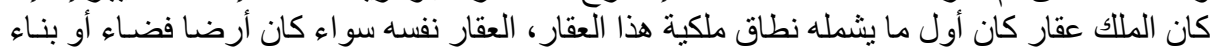

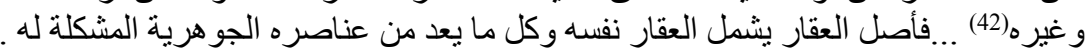

المطلب الثانى : العلو والعمق : العز

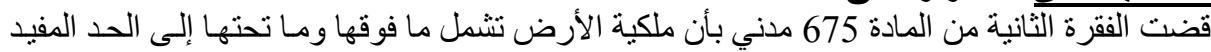

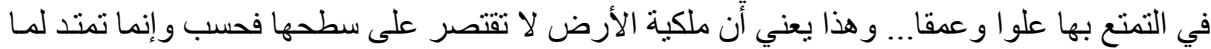
فوقها من فضاء و هو العلو وما تحتها من أعماق ونعرضية الارضهما في الفرعين التاليين:

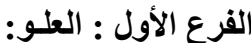

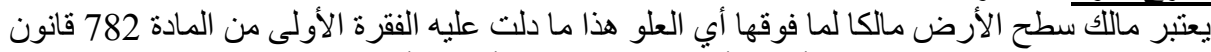

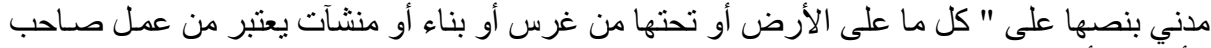
الأرض و أقامه على نفقته ويكون مملوكا لها له". 
فهذه الفقرة من المادة تفيد أن ملكية سطح الأرض قرينة على ملكية ما فوقها لكن هذه القرينة بسيطة

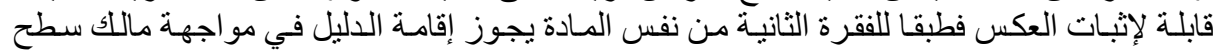

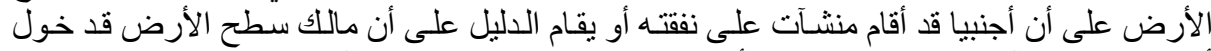

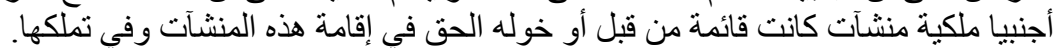

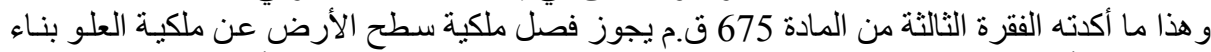

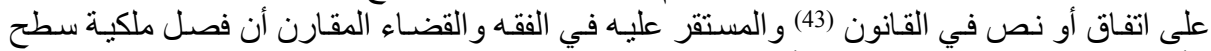

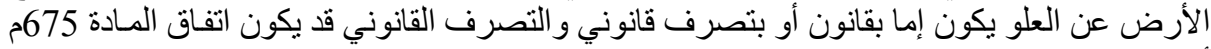

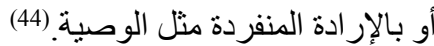

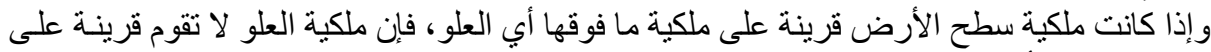

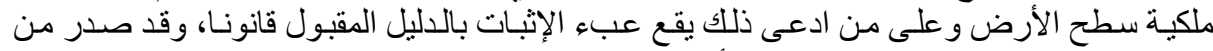

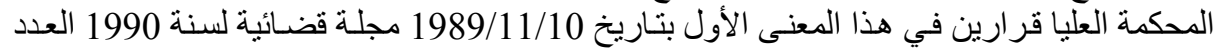

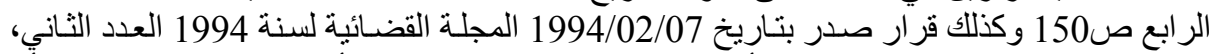

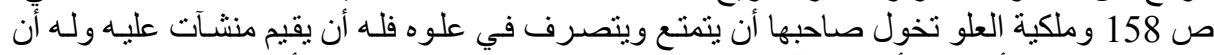

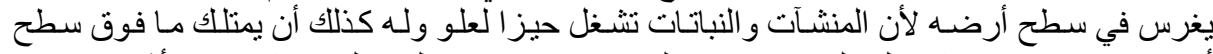

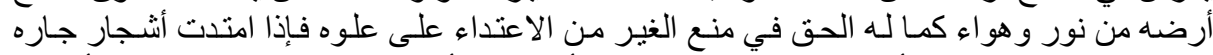

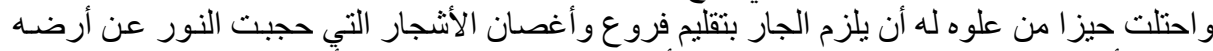

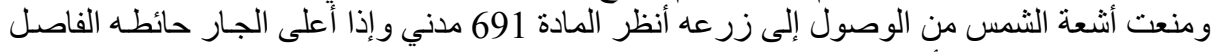

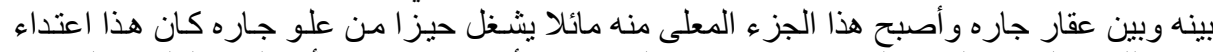

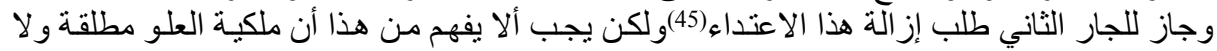

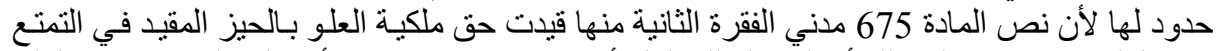

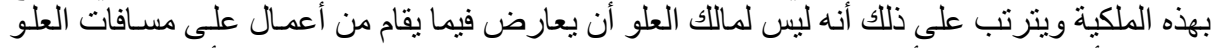

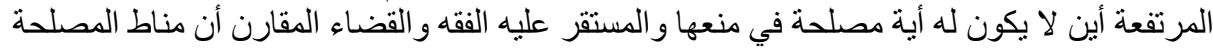

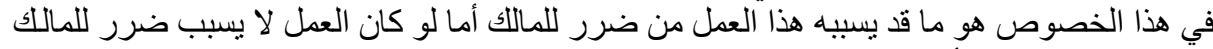

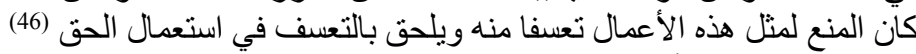

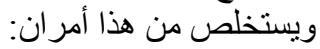

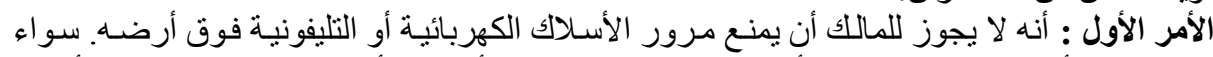

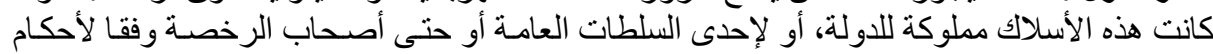

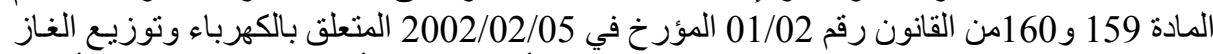

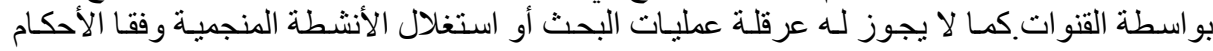

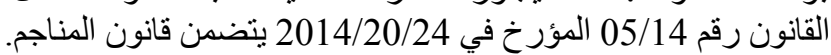

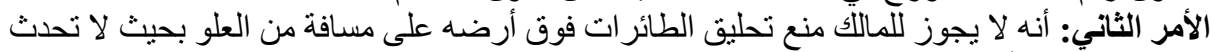

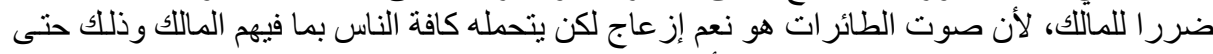

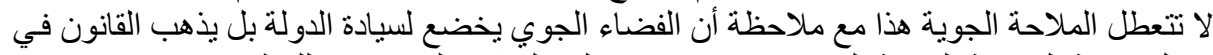

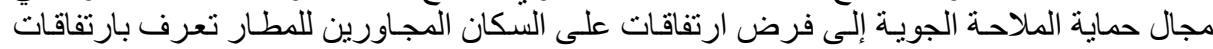

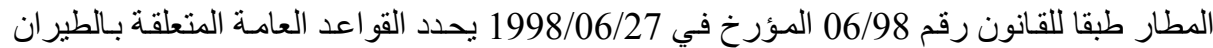

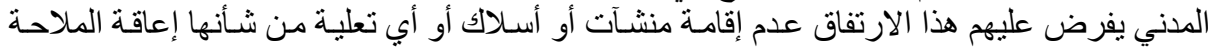

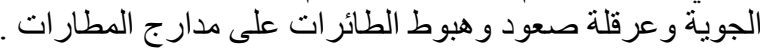

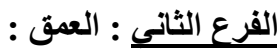

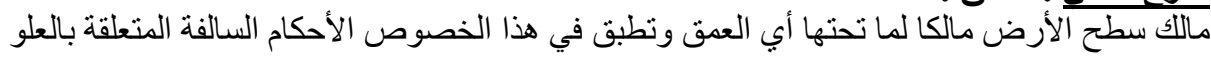

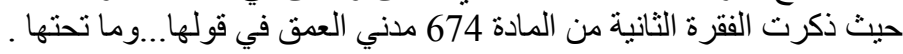


ومالك سطح الأرض تمنحه هذه الملكية قرينة بسيطة قابلة لإثبات العكس بنفس الفقرة الأولى من المسادة

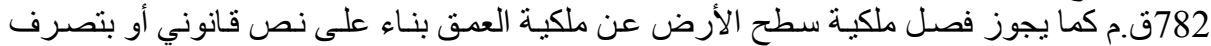

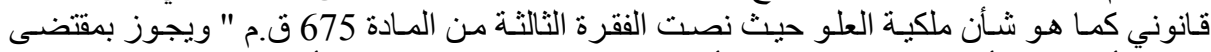

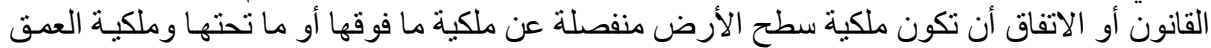
ليست قرينة على ملكية سطح الأرض فإذاذا ادعى ماللك العمق ملكية سطح الأرض علية فليه عبء الداليل

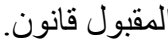

وملكية صاحب سطح الأرض اللعمق تخوله الحق في حفر أرضه أو عمقاه لوض لوضع أسس البناء الذي يريد

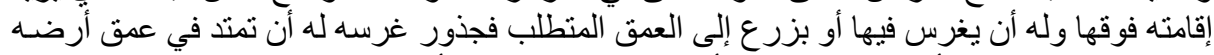

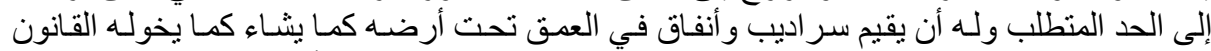

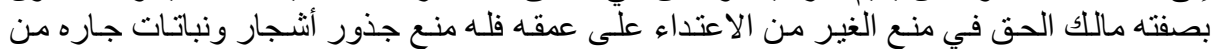

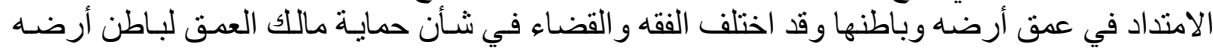

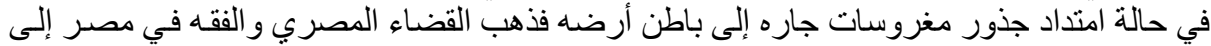

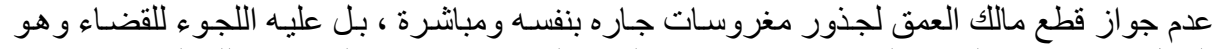

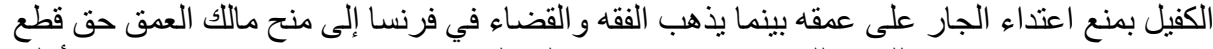

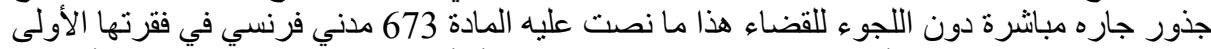

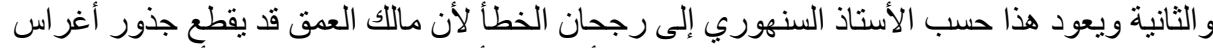

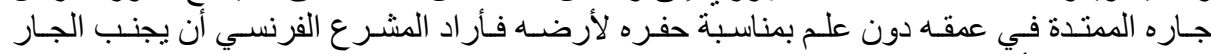

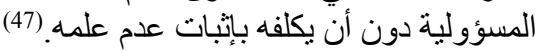

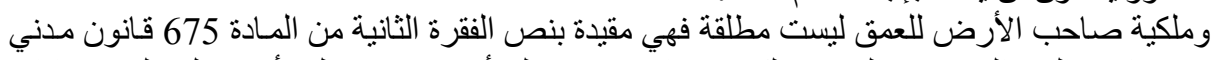

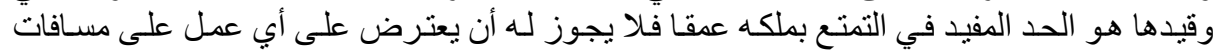

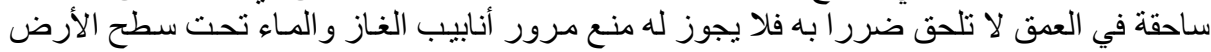

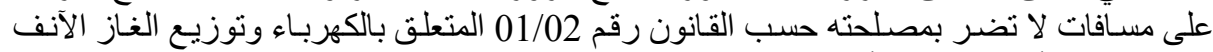

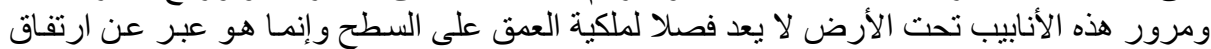

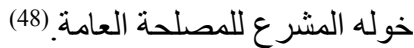

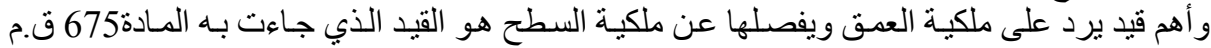

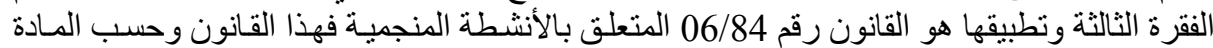

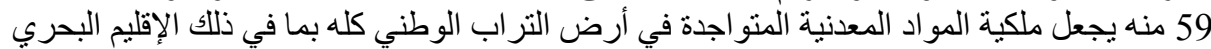

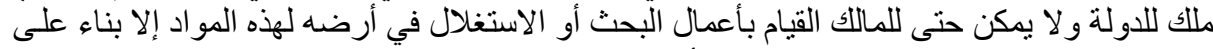

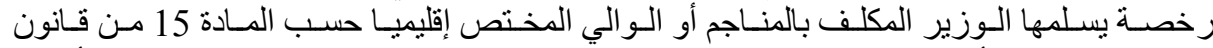

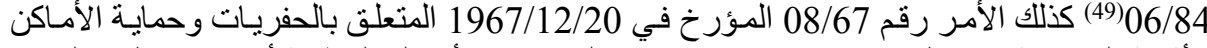

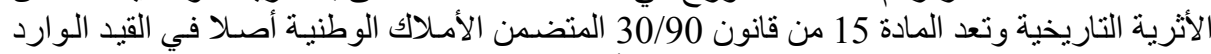

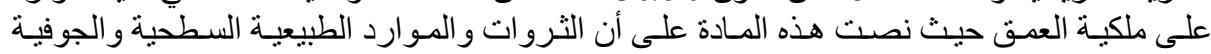

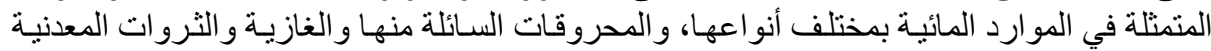

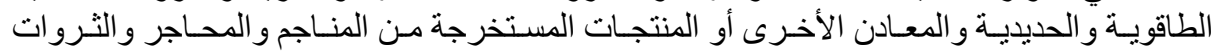

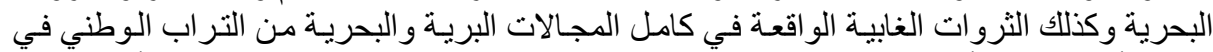

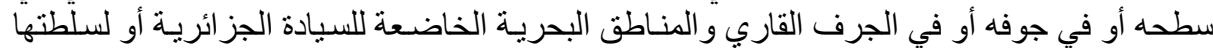

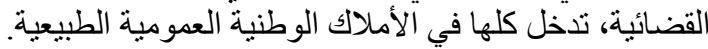

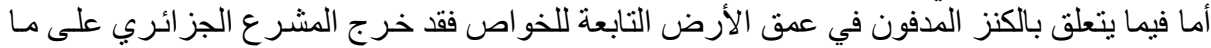

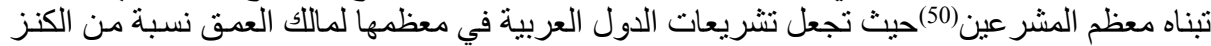

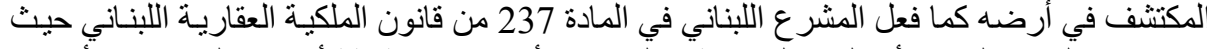

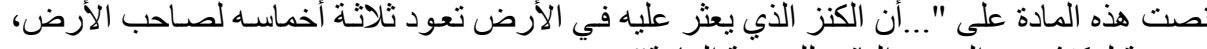

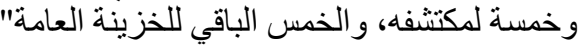




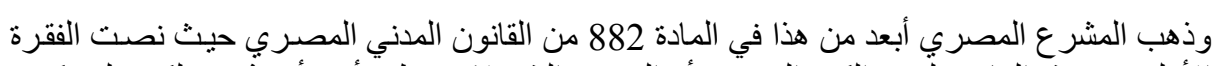

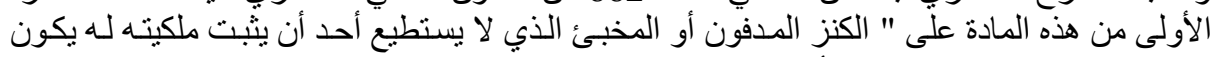

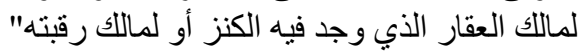

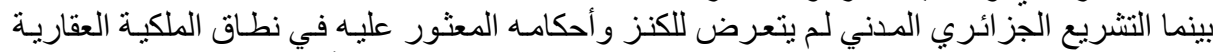

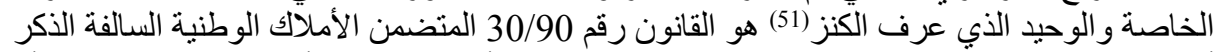

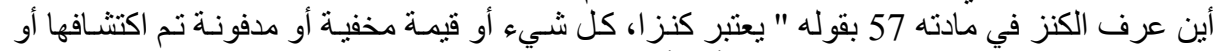

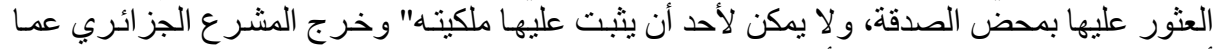

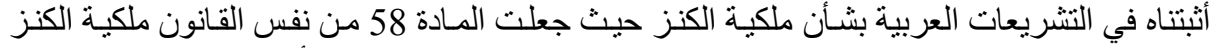

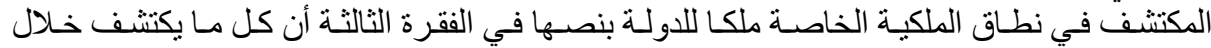

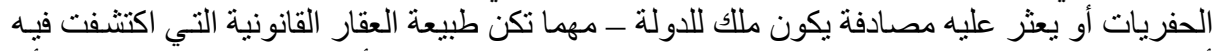

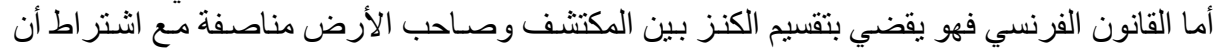

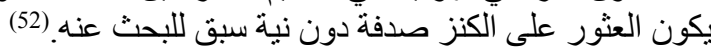

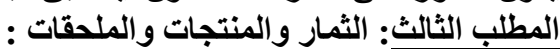

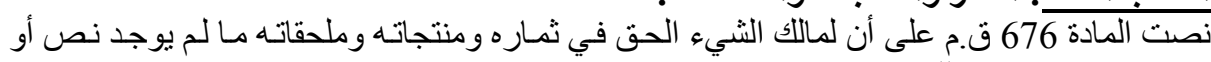
اتفاق يقضى بخلاف ذلك الك.

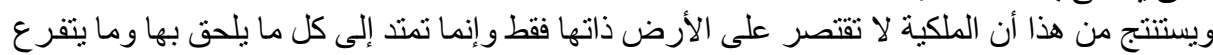

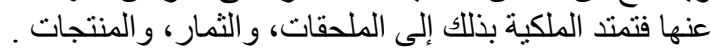

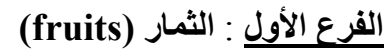

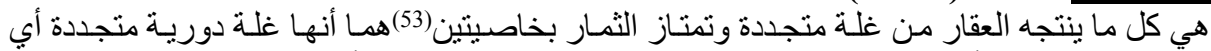

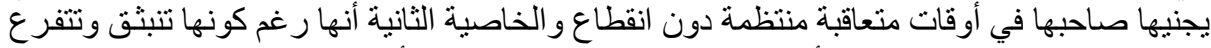

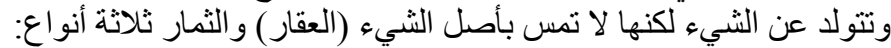

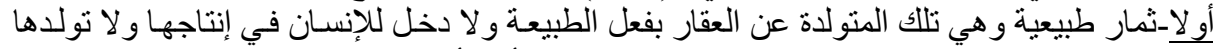

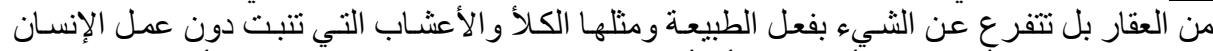

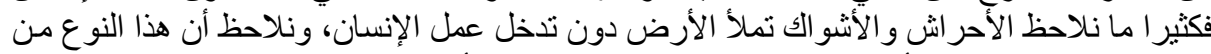

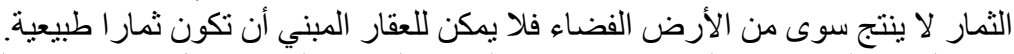

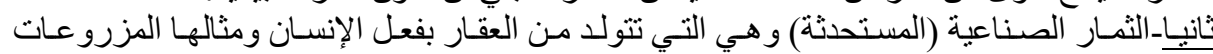

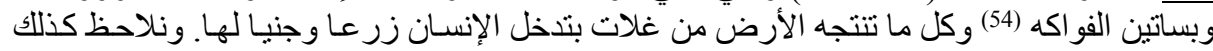

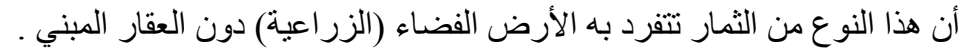

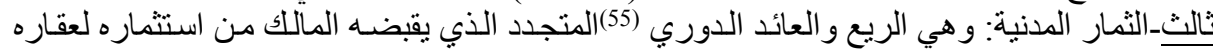

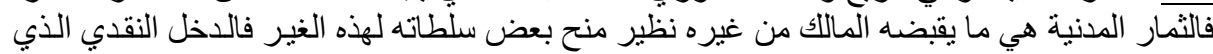

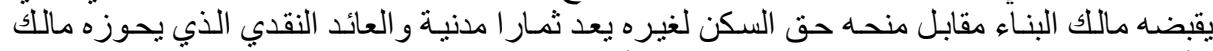

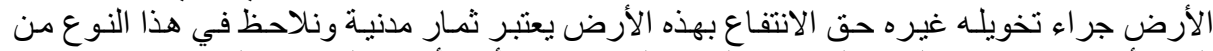

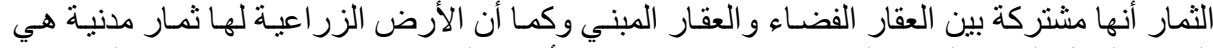

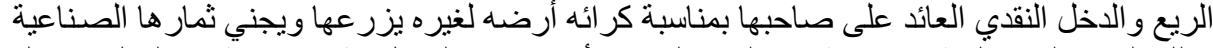

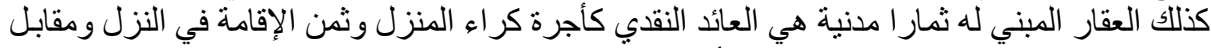

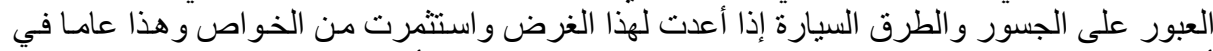

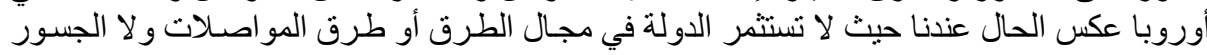
الموصلة، اللهم الضريبة المفروضة المبة على مالكي العربات كل سنة.

الفرع الثانى : المنتجات (produits) 
هي كل ما يخرج من العقار من ثمار ات غير متجددة (56) فالمنتجات تختلف عن الثمار في كونها غير إندار

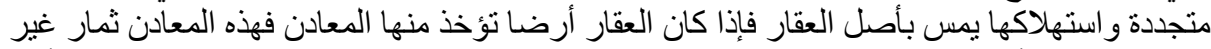

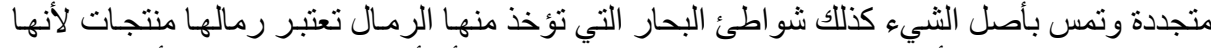

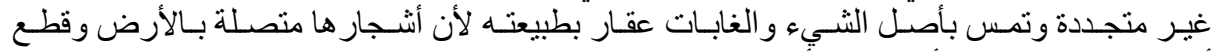

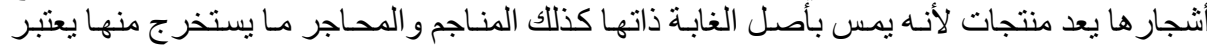

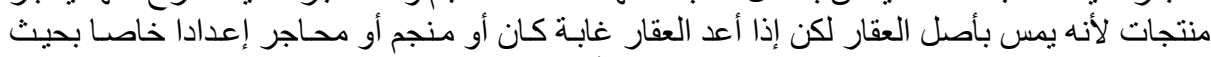

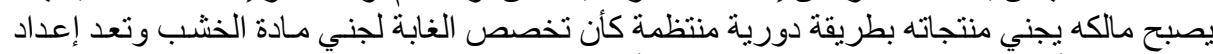

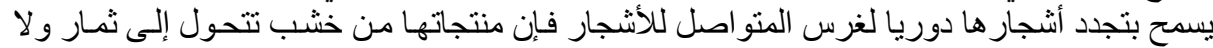

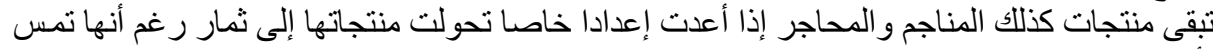

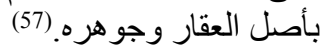

ونلاحظ كذلك أن العقار المبني ليس له منتوجات بالمفهوم الأول بل لا يتولد عنه سوى الثمار المدنية.

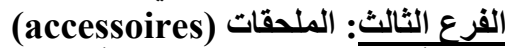

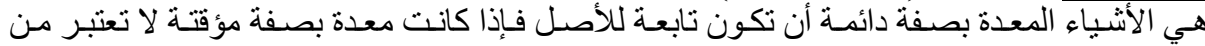

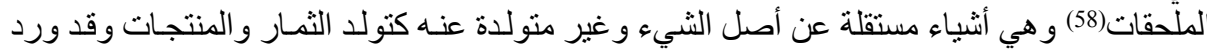

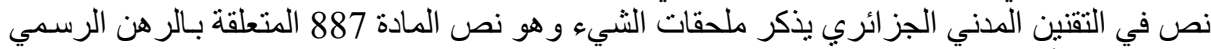

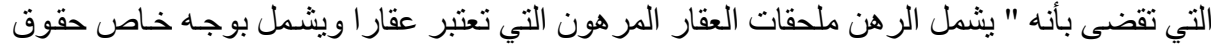

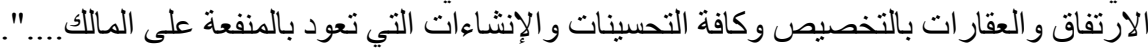

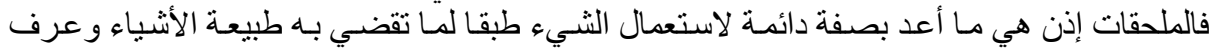

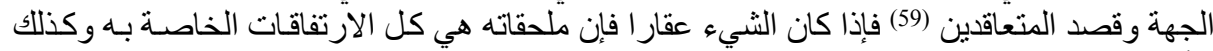

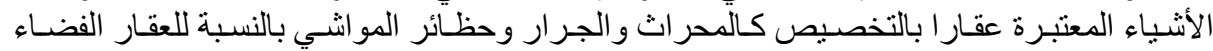

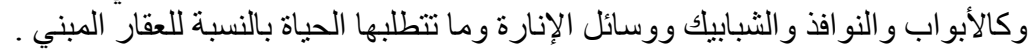

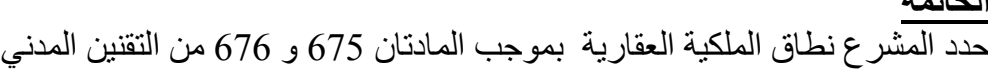

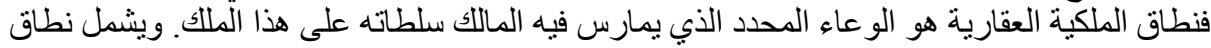

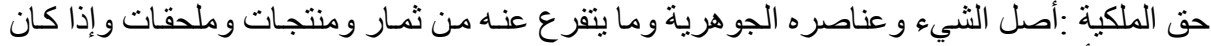
هذا الملك أرضا شملت ملكيتها ما فوقها وما التحا تحتها إلى الحد المفيد في التمتع بها.

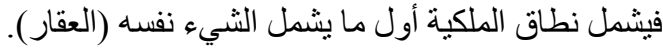

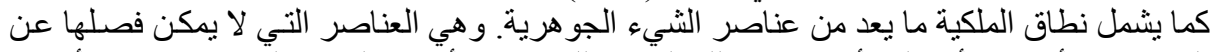

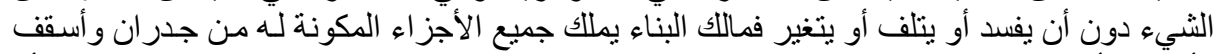

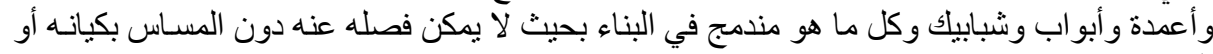

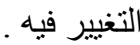

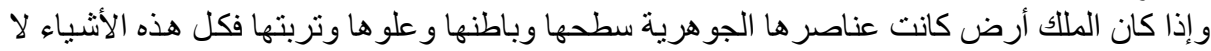

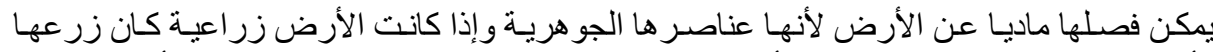

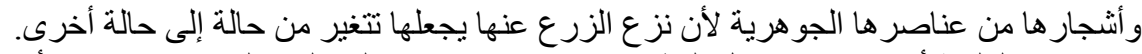

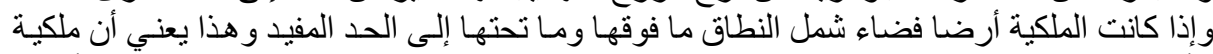

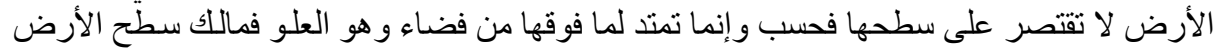

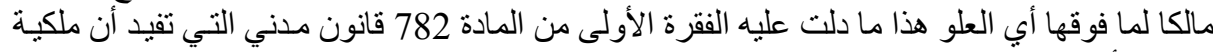

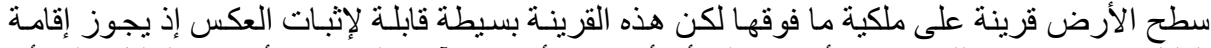

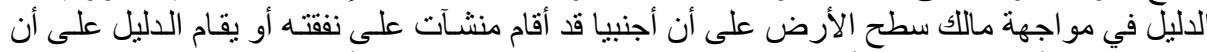

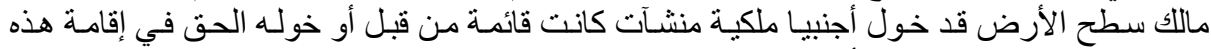
المنشآت وفي تملكها. و هذا ما أكدته الفقرة الثالثة من المادة 675 ق.م. 


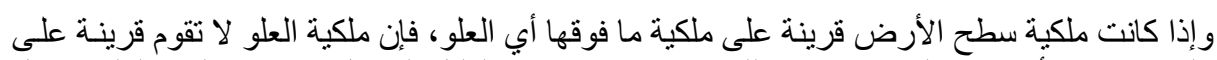

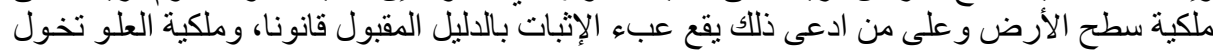

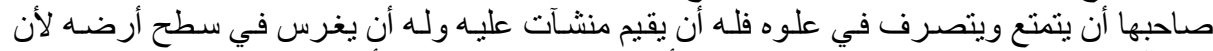

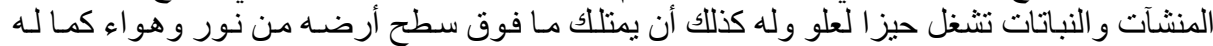

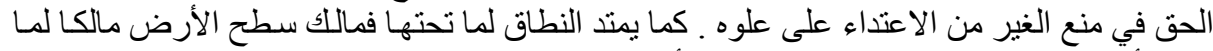

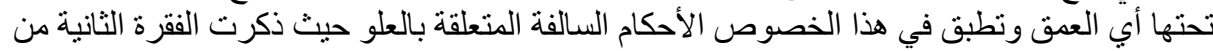

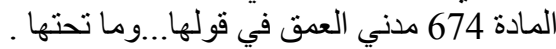

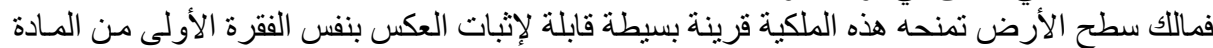

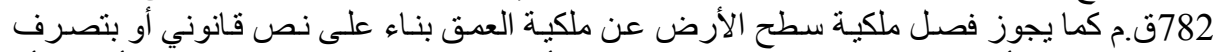

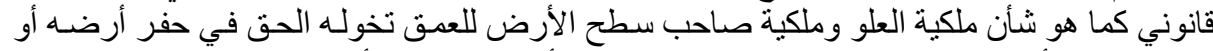

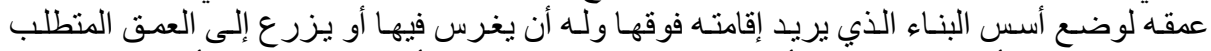

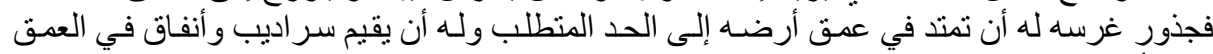

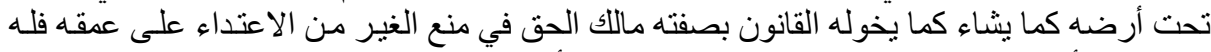

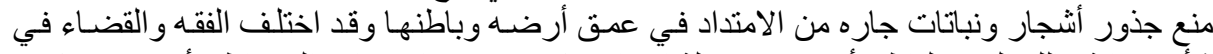

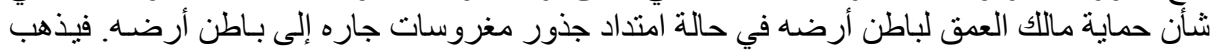

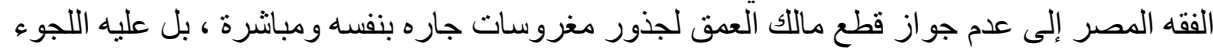

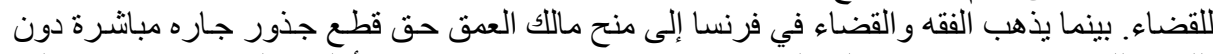

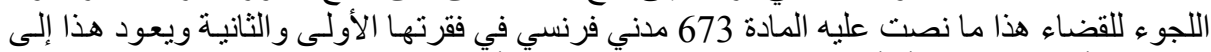

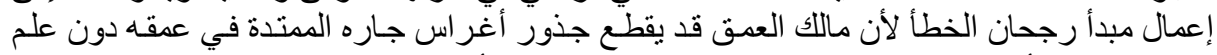

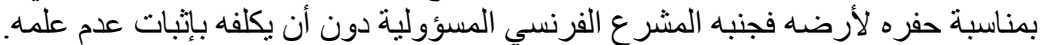

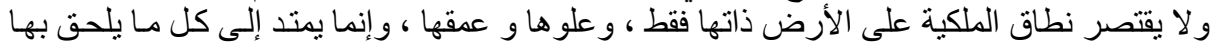

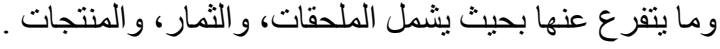

الهو امش والمراجع المبع

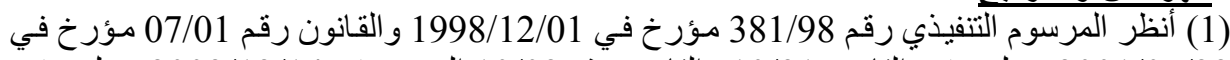

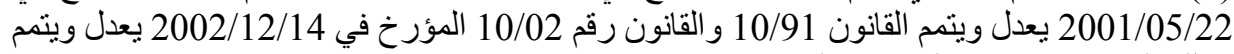

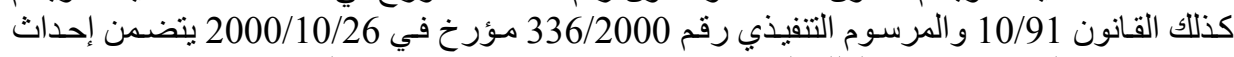

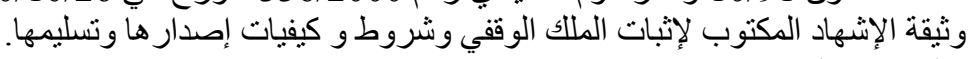

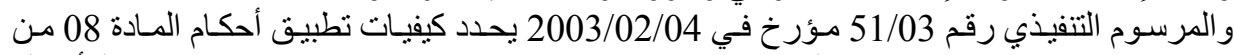

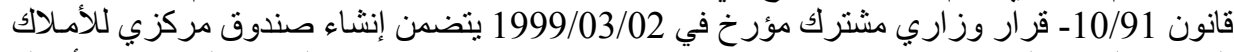

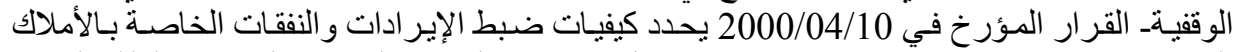
الوقفية، ـقرار مؤر خ في 2001/05/26 يحدد شكل ومحتوى الثهادة الرسمية الخاصـة بالملك الوقفي لألفي

(2) أنظر المواد من 33 إلى 37 من قانون 25/90.منعلق بالتوجه العقاري.

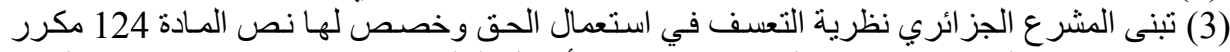

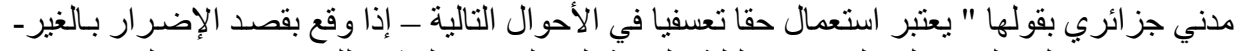

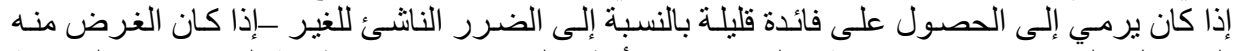

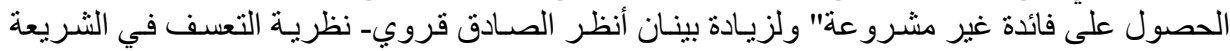

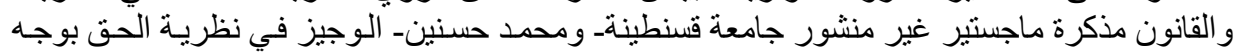

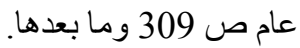




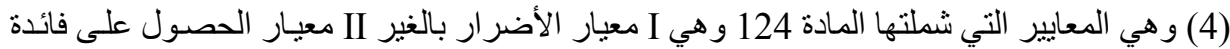

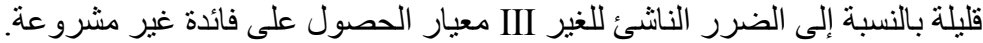

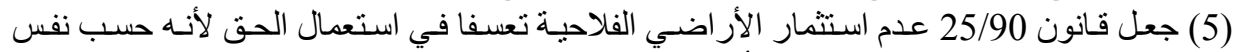

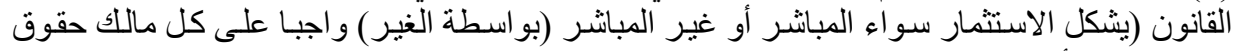

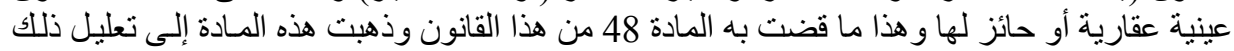

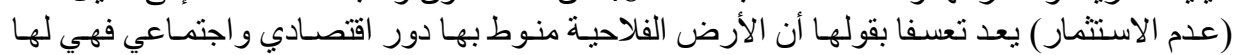

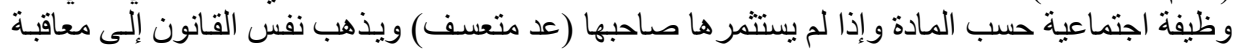

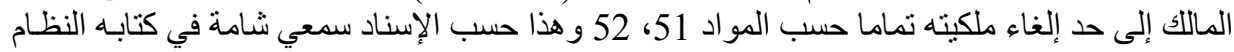

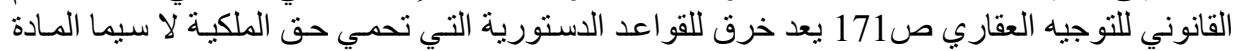

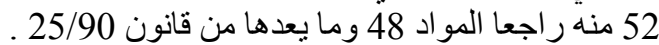
(6) (6صد هنا الملكية العقارية الخاصة.

(7)نقصد بالدستور، دستور 1989/02/23 لأن استفتاء 1996/11/28 جاء بعد قانون 25/90 و انظر المادة 52 من دستور 1996.

(88) من خصائص الأملاك العامة عدم قابليتها للحجز و لا لتصرف فيها و لا تمتلك بالثقادم انظر المـادة

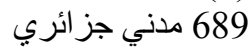

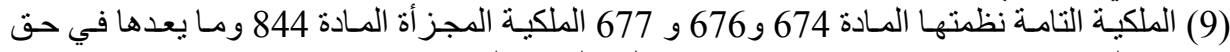

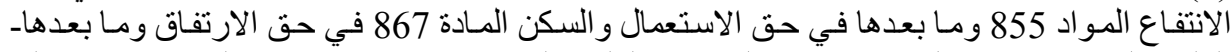

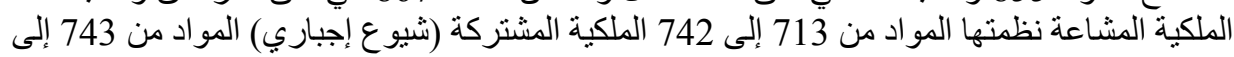

(10) رمضان أبو السعود: الوجيز في الحقوق العينية الأصلية (أحكامهاومصادرها)، نشر دار الجامعة

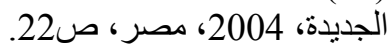

(11) السنهوري: الوسيط، المجلد 8 الباب الأول، القسم الثاني، منشورات الحلبي، بيروت، 1998، ص

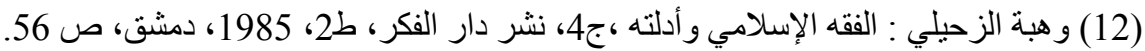
(13) Voir. Dalloz: Répertoire de droit civil, $2^{\mathrm{e}}$ édition, mise a jour 1977, tome VI, recueil VO propriété sect. $1^{\text {er }}$ étude général du droit de propriété, Paris, p1. (14) « La propriété est, le droit de jouir et disposer des choses de la manière la plus absolue pourvu qu'on n'en fasse pas un usage prohibe par les lois ou par les règlements "

voir: Henri et Léon MAZE AUD, jean mazeaud, François chabas- leçons de droit civil, $8^{\mathrm{e}}$ édition, tome II, deuxième volume, Montchrestien, Paris, p9 .

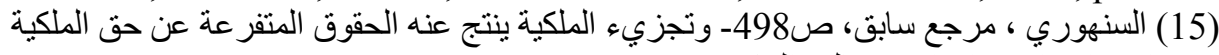

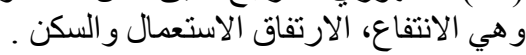

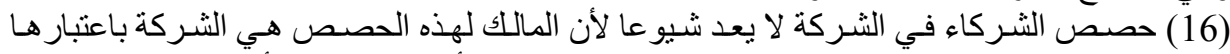

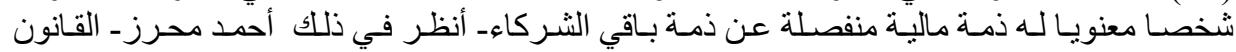

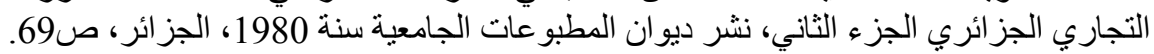

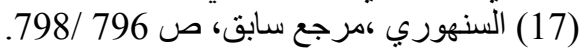

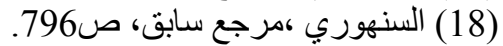

(19) أنظر الآية 11 من سورة النساء/مع ملاحظة أن المثال ليس فيه نصيب للزوجة (1/1) لأنه غير مذكورة في المثال (20) مثاله أن يثتري عدة أنثخاص قد يكونوا من أسرة واحدة عقار ا على الثيوع دون تحديد نصيب كل و احد منهم. 
(1) أنظر المواد 722-723 -727 إلى 737 وكذلك رمضان أبو السعود ـ المرجع السابق، ص 72 وما

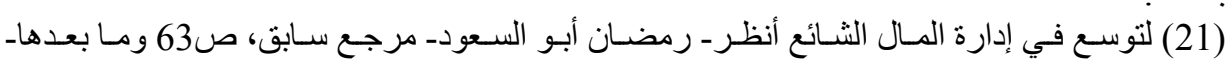

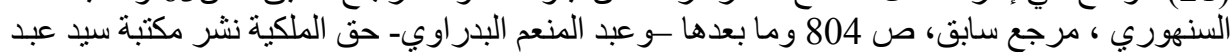

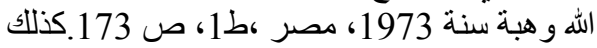

Jean mazeaud.Henri et léon mazeaud. François chabas- leçons de droit civil tome II Biens droit de propriété 52 édition. Montchrestien 1994, P 40

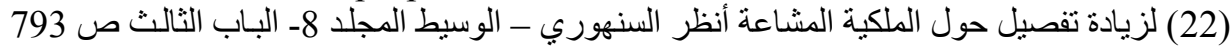

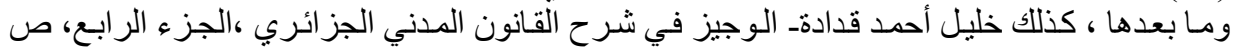

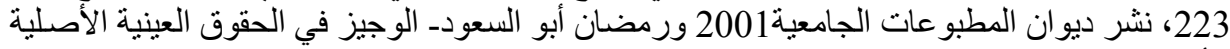

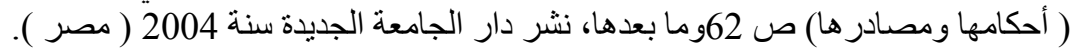

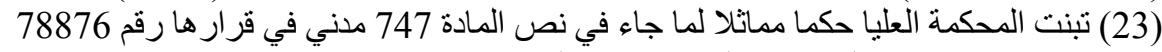

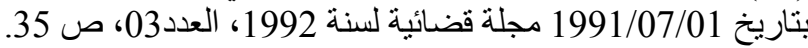

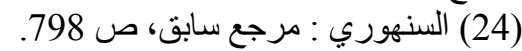

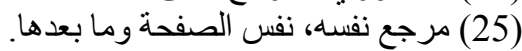

(26) أنظر -أعمر يحياوي- نظرية المال العام، نشر دار هومة، 2002، الجز ائر ، ص 51.

(27) رمضان أبو السعود : مرجع سابق، ص 93.

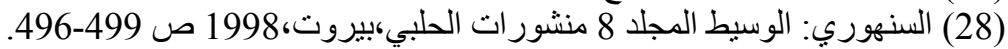

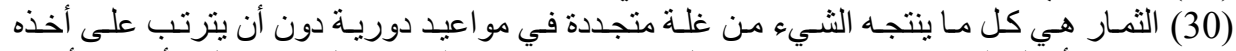

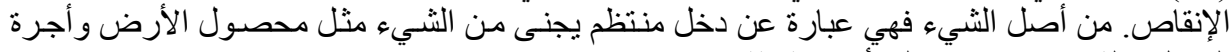

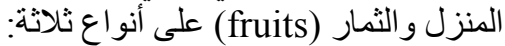

ـ الثمار الطبيعية وهي من عمل الطبيعة لا دخل للإنسان في إنتاجها مثل الأعثاب و الكلاً التي تتبت

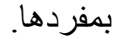

ـ ـ الثمار المستحدثة هي التي يكون للإنسان يد في إنتاجها (تمار صناعية).

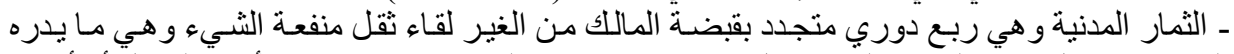

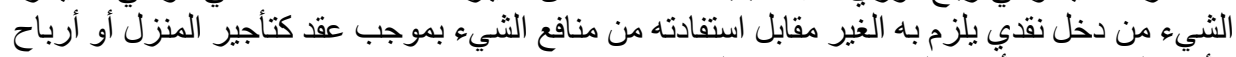

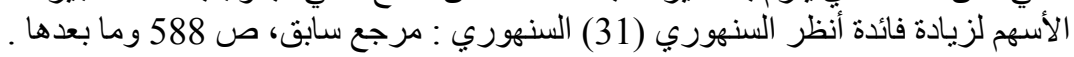

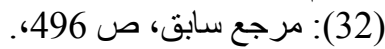

(33) المنتجات هي ما ينتجه الثيء في مو الثيد الثيد دورية ويترتب على أخذها الانتقاص من أصل الثيء

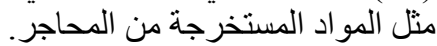

(34) أنظر .عمار نكاع ، النظام القانوني للعقار الغابي وطرق حمايته في التثريع الجزائري، رسالة

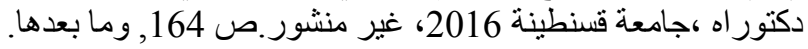

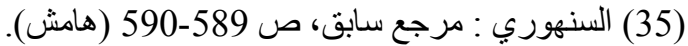

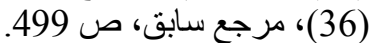

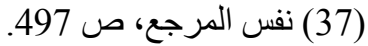

(38) التصرف المادي يرد على الثيء محل الحق لهذا كان التصرف المادي العنصر الوحيد الذي يميز

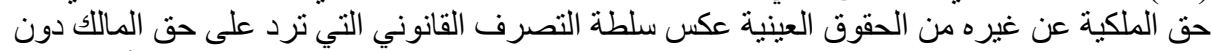

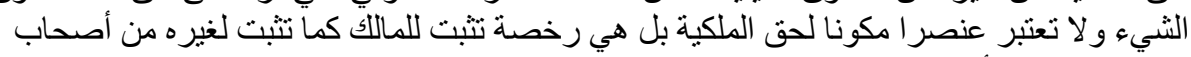

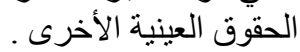




$$
\begin{aligned}
& \text { (39) جاء في المادة } 674 \text { مدني جز ائري ما يلي ـ الملكية هي حق التمتع و التصرف في الأشياء بشرط }
\end{aligned}
$$

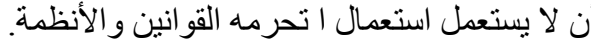

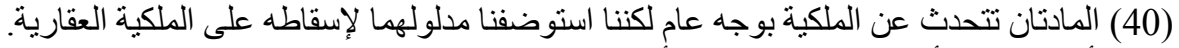

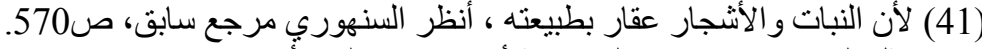

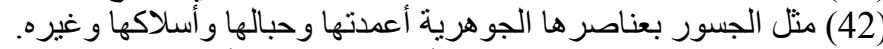

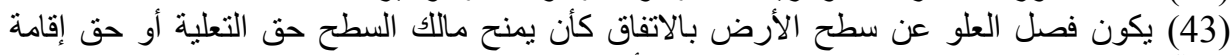

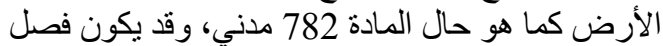

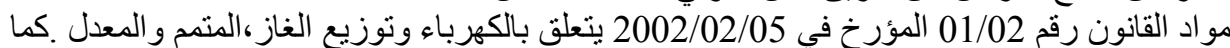

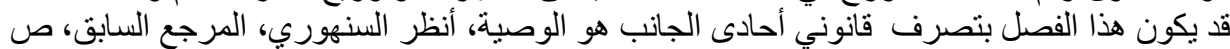

$$
\begin{aligned}
& \text { (44) أنظر المادة } 190 \text { من قانون الأسرة . }
\end{aligned}
$$

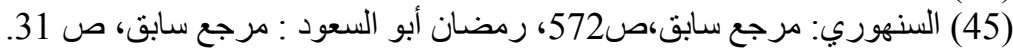

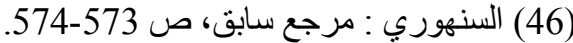

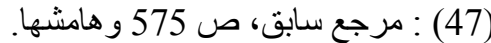

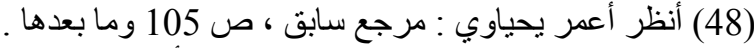

(49) محمد وحيد الدين سوار : الحقوق العينية الأصلية، نشر مكتبة الثقافة للنشر والتوزيع ، التعائ ، الأردن،

(50) أنظر في تعريف الكنز و أحكامه وحيد الدين سوار ، الحقوق العينية الأصلية، نشر مكتبة الثقافة

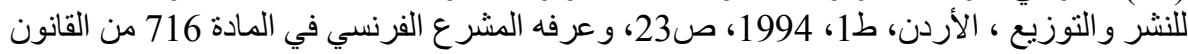
المدني في قوله :

"toute chose cachée ou enfouie sur la quelle personne ne peut justifier sa propriété et qui est découverte par le pur effet du hasard"

(51)françois chabas -leçons de droit civil- biens $8^{\mathrm{e}}$ édition -montcherstien , paris, p313.

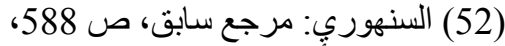

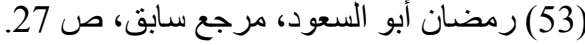

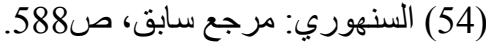

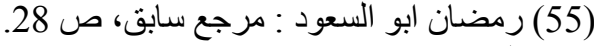

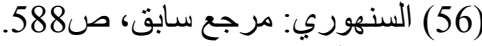

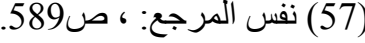

$$
\begin{aligned}
& \text { (58) مرجع سابق، ص587. } \\
& \text { (59) قد يتفق المتعاقدين على أن ملكية الثيء تنفصل عن ملكية ملحقاته }
\end{aligned}
$$

